\title{
New Product Success in the Consumer Packaged Goods Industry: A Shopper Marketing Approach
}

\author{
Lien Lamey* \\ Barbara Deleersnyder \\ Jan-Benedict E.M. Steenkamp \\ Marnik G. Dekimpe
}

Lien Lamey is Associate Professor of Marketing, KU Leuven, Belgium (e-mail: lien.lamey@kuleuven.be). Barbara Deleersnyder is Associate Professor of Marketing, Tilburg University, the Netherlands (e-mail: b.deleersnyder@uvt.nl). Jan-Benedict E.M. Steenkamp is C. Knox Massey Distinguished Professor of Marketing and Marketing Area Chair, University of North Carolina at Chapel Hill (e-mail: JBS@unc.edu). Marnik G. Dekimpe is Research Professor and Marketing Area Chair, Tilburg University, the Netherlands, and Professor of Marketing, KU Leuven, Belgium (e-mail: m.g.dekimpe@uvt.nl).

*corresponding author (lien.lamey@kuleuven.be - Naamsestraat 69 B3000 Leuven, Belgium)

We thank AiMark for providing the data. This work was financially supported by GfK Verein; the Marketing Science Institute (grant number \#4-1684); the Netherlands Organization for Scientific Research (grant number 452-10-004); and the Flemish Organization for Scientific Research (grant number G057014N). 


\title{
New Product Success in the Consumer Packaged Goods Industry: A Shopper-Marketing Approach
}

\begin{abstract}
Marketing activities that influence shoppers along the various stages of their path-to-purchase are gaining attention from both manufacturers and retailers. Using a dataset with detailed information on 105 new products (NPs) launched in the U.K. by 44 leading brands and sold across 13 major retail banners, we provide strong support for the prominent role of both upper- and lower-funnel marketing actions that influence consumers before (upper) or during (lower) their shopping trip. We show which of these shopper-marketing instruments have the largest effect on NP performance at a retailer, and whether and how their effect is moderated by the retailer's store context. When it comes to NP success, the lifeblood of CPG companies, the lower-funnel marketing actions targeting shoppers directly at the point-of-purchase predominantly decide your fate. Thus, manufacturers should work ever harder to collaborate with retailers and push the storespecific shopper-marketing instruments in a favorable direction through information sharing and tailoring of their marketing program to individual retailers. Indeed, not all news is bleak for brand manufacturers. We identify five pieces of good news that brand manufacturers can use to their advantage.
\end{abstract}

Keywords: New products, Shopper marketing, Retailing, Brands, Store context. 


\section{Introduction}

For consumer packaged goods (CPG) manufacturers, the introduction of new products (NPs) is recognized as one of the most important marketing activities (Sorescu and Spanjol 2008). Thus, it is not surprising that brand manufacturers spend significant resources on the development and launch of NPs. Unfortunately, despite these efforts, a large majority of new CPG products fail in the marketplace (Gielens and Steenkamp 2007). Consequently, the question what drives NP success in the CPG industry has attracted considerable research attention (e.g., Ataman, Mela, and van Heerde 2008; Steenkamp and Gielens 2003).

While important, earlier studies have often focused on the overall, market-level effect on NP sales of marketing-mix instruments like advertising and NP innovativeness that influence consumers in the pre-purchase stage of the consumer purchase cycle (Lemon and Verhoef 2016). More recently, an expanded perspective has been proposed that focuses on the entire path-topurchase customers go through. In this view, firms should design and manage the entire process a customer engages in before making a purchase (Lemon and Verhoef 2016, p. 71). This new perspective, sometimes called shopper marketing, emerged in the wake of studies that found that $50-70 \%$ of shoppers' decisions are made in-store (Shankar 2011). It encourages manufacturers to broaden their thinking and manage national brands (NBs) across multiple stages along the purchase funnel (Lemon and Verhoef 2016), and to also consider how retailer-specific activities in the store influence the ultimate purchase decision (Shankar 2011).

However, two important considerations arise when adopting such a broader view that considers the entire customer journey. First, while manufacturers are in control of the upper-funnel marketing activities (related to branding, advertising and product innovativeness), competition laws in many countries, including the U.S. and the U.K., have limited the ability of manufacturers to enforce the retail prices of their goods. Nevertheless, manufacturers attempt to negotiate with 
their main retail clients to jointly decide on retail prices while both the manufacturer and the retailer exert some influence on the promotion calendar (Guyt and Gijsbrechts 2014). Also, literature on retailer pass-through (e.g., Ailawadi and Harlam 2009) shows considerable variability in promotional pass-through. This supports the notion that even if the retailer ultimately is in control of pricing and promotional decisions in its stores, such decisions are influenced (and, in case of promotions, often funded) by the manufacturer.

Second, the shopper-marketing approach emphasizes that product success varies in function of the retail-shopper environment, recognizes the importance of both out-of-store and in-store marketing stimuli, and allows for the distinct possibility that the effectiveness of marketing efforts can - and will - vary based on the shopper retail context. This applies not only to the lower-funnel marketing stimuli at the actual point-of-purchase; also the effect of upper marketing actions may not be the same across store contexts. If anything, this holds especially for decisions related to the purchase of NPs, as these decisions are not yet part of consumers' habitual buying behavior that characterizes most CPG purchases. As a result, NPs can be very successful in some retail contexts but less so in others.

So, to improve NP performance, brand manufacturers need to move from traditional marketing to shopper marketing that (1) considers marketing actions along the entire path-topurchase, and (2) allows for retailer-specific influences. In the words of Shankar et al. (2011, p. S36), “[T]he programs must be customized to the retailer's shopper base. The days of cookie cutter programs are a thing of the past." This observation provided the impetus for our study. We will investigate the effects of both market-level, out-of-store shopper-marketing variables that are under the control of the NB manufacturer, as well as retail specific, in-store marketing actions that are the outcome of frequent negotiations between a manufacturer and each individual retailer on the performance of the NP at that retailer. We also consider whether and how the effectiveness of 
these shopper-marketing instruments is moderated by the general and category specific store context in which NP purchases take place.

Our research seeks to provide an initial answer to the following four research questions. First, how important is shopper marketing in determining NP performance at the retailer? Is it really the important driver that shopper-marketing enthusiasts envisage? Second, what is the collective importance of the manufacturer-controlled, out-of-store shopper-marketing variables versus retailer-manufacturer negotiated, in-store shopper-marketing variables in explaining NP success? Is NP performance largely driven by manufacturer market-level actions or do retailer-specific factors take the front seat? Or are they roughly equally important? The implications for the relative power of manufacturer versus retailer are profoundly different. Third, what is the substantive impact of the different shopper-marketing variables in driving NP performance? While the direction of most drivers is, arguably, well-established, we know less about their relative impact on NP success. Fourth, to what extent do the effects of the various shopper-marketing variables differ according to the store context in which the NP is sold?

Collectively, the answers to these research questions provide brand manufacturers with important shopper-marketing insights. This not only allows them to develop more effective shopper-focused, as well as trade-targeted, NP marketing strategies per se, but also provides a platform to work towards a better strategic alignment between retailers and brand manufacturers. The insights generated by this study are based on the performance of 105 NPs launched in the U.K. across $21 \mathrm{CPG}$ categories by 44 leading NBs during a three-year period. We will evaluate the success of each NP across 13 leading U.K. retail banners from 10 retail firms.

\section{Research Framework}

Our focal variable is NP performance at an individual retailer, which is operationalized as the NP's category share at that retailer in the year after that retailer included it into its assortment. 
Industry studies (Ernst\&Young/ACNielsen 2000) and academic research (Steenkamp and Gielens 2003) regard the first year to be crucial for the success of new CPGs.

Our research framework (Figure 1) conceptualizes the impact of various marketing-mix instruments around the marketing funnel. The marketing funnel is especially popular among practitioners (e.g., Court et al. 2009; Rubinson 2010). In our funnel, we distinguish between upper- and lower-funnel shopper-marketing variables. By taking into consideration the entire pathto-purchase, shopper marketing emphasizes the complimentary importance of upper-funnel (mainly out-of-store) marketing stimuli that influence consumers early in the purchase cycle and lower-funnel marketing stimuli that affect shoppers once they enter the store (Shankar et al. 2011). --- Insert Figure 1 about here ---

We use this insight to identify two groups of marketing-mix variables that affect NP performance. The first group consists of upper-funnel shopper-marketing variables that influence consumers before they enter the store. These factors can - and often do - exist distinct from any particular retailer, and are under the exclusive control of the brand manufacturer. Using the 4P's as organizing framework, the key instruments under the exclusive control of the brand manufacturer are the product - where we consider both the brand equity of the mother brand under which the $\mathrm{NP}$ is introduced and the innovativeness of the NP - and the advertising component of the promotion mix.

The second group consists of shopper-marketing variables that influence consumers directly while they are shopping in the store. Here, in terms of the 4Ps, we consider the NP's price (relative to the category price) and the price-promotion component of the promotion mix. Note that both of these in-store variables are specific to any individual retailer. Collectively, our set of five drivers are among the marketing instruments that are widely considered as highly relevant in explaining NP success. 
Another tenet of shopper marketing is the importance of the store context in purchase decisions (Shankar 2011). Our research framework distinguishes between retailer-wide storecontext effects as opposed to context effects at the category level in which the NP is offered. It includes three store-context factors - one at the retailer level (the brand equity associated with the retail banner itself) and two at the category level (category private-label (PL) share and NP uniqueness relative to the retailer's established category offerings).

In our conceptualization, we outline two ways in which the store context affects NP performance (Figure 1). First, there is the direct effect in that we expect that NP performance varies systematically across store contexts. Second, we allow for the possibility that the effectiveness of specific shopper-marketing variables depends on the store context. Shoppermarketing theory is not sufficiently developed yet to advance a comprehensive set of a priori expectations concerning the moderating effects of particular store-context factors on specific NP drivers. Therefore, following Steenkamp and Geyskens (2014), we use inductive reasoning to investigate the moderating role of the store context. In the next section, we develop the rationale underlying the expected main effects of the key variables.

\section{Drivers of NP Performance at the Retailer}

\subsection{Upper-funnel shopper-marketing activities}

Brand equity (+). The NP benefits from being sold under a high-equity brand name as consumers can plausibly believe that the NP is also of high quality. The incentive to cheat by extending the reputable brand with a low-quality product is reduced by the loss of repeat sales of the NP, the loss of repeat sales of other products sold under the same brand name, and the loss of future sales due to the reduced extension potential of the brand (Erdem 1998; Klein and Leffler 1981). 
Brand advertising (+). Advertising influences the early stages of consumers' path-topurchase by building NP awareness and activating the motivation to buy it. Heavy advertising is also a signal for NP quality. The rationale is that firms spend money up-front, expecting to recover it through future sales. These marketing investments will be lost if the firm cheats on its assurance of quality, and thus, rational consumers can reliably use advertising as a signal to infer the NP's quality (Klein and Leffler 1981).

NP innovativeness (+). Following Sorescu and Spanjol (2008) and Lamey et al. (2012), we distinguish between breakthrough NPs and incremental NPs. These authors define breakthrough innovations in the CPG industry as NPs that are the first to bring novel and significant consumer benefits to the market. These benefits may come in different forms ranging from improvements to product features, such as packaging (e.g., yogurt packaged in a tube that eliminates the need for a spoon or refrigeration), to opening up an entirely new market (e.g., homemade sugar-free jam by

allowing customers to make freezer jam with a higher fruit content and less sugar than the pectin method), or introduction of a new technology (e.g., wrap that seals to various surfaces, including paper, plastic, and wood, using a proprietary gripping technology) (Sorescu and Spanjol 2008, Table 2). Incremental innovations are NPs that deliver minor consumer benefits. We can expect that the performance of breakthrough manufacturer innovations exceeds that of incremental NPs (Sorescu and Spanjol 2008).

\subsection{Lower-funnel shopper-marketing activities}

NP price premium (-). All things equal, economic theory suggests that the higher the average price of the NP relative to in-store alternatives in the product category, the lower the inclination of shoppers to buy the product. Steenkamp and Gielens (2003) found that the trial probability was lower for high-priced NPs.

NP promotion intensity $(+)$. NPs need to gain a foothold in the market and shoppers will 
recognize that firms use promotions to stimulate trial (Steenkamp and Gielens 2003). The marketing literature provides strong support for the effectiveness of price promotions in increasing sales.

\subsection{The role of the store context}

Retailer-wide store context: $R B B E(+)$. The retail banner is a brand in its own right, affecting shopper response, and creating value to the company (Ailawadi and Keller 2004; Kumar and Steenkamp 2007). The retail banner acts as an umbrella brand spanning the entire assortment. From an information-economics perspective (Erdem 1998), when consumers are uncertain about the product's quality, purchasing the product at a retailer with high RBBE lowers their perceived purchase risk, which is especially important for NPs as they are inherently riskier than existing ones (Steenkamp and Gielens 2003).

Category-specific store context: PL share (-). In categories where the retailer's PL has succeeded in capturing a large share of total sales, the performance of NPs introduced by a brand manufacturer is likely to be lower. In these categories, many people have gotten used to buying PLs, and have become less inclined to even consider buying branded products (Lamey et al. 2007).

Category-specific store context: Uniqueness (+/-). The same NP can be very unique in the category at one retailer, but not so much at a competing retailer. We operationalize differences between product offerings using two pertinent assortment attributes - package size (ter Braak, Dekimpe, and Geyskens 2013a) and the number of sub-brands (i.e., brand-product varieties such as Quaker Oat Crisp, Quaker Oat Crunch, etc.; Morgan and Rego 2009) that bear the same mother brand name (i.c., Quaker) as the NP. If the package size is different from other products already offered by the retailer or if the mother brand is not well-represented in the assortment, this indicates higher uniqueness. One could argue that high uniqueness has a positive impact on NP sales as the NP stands out more against the backdrop of other offerings in the category. On the 
other hand, CPG shopping tends to be of a routinized nature, and shoppers who are in a routinized shopping mode might have formed the habit of purchasing a particular package size. They also may not notice the NP brand as hitherto it had not featured prominently in the retailer's category assortment. This should have a dampening effect on NP performance.

\subsection{Covariates}

Several other covariates are included in our framework (Figure 1) and analyses. First, NP speed of adoption varies because retailers often do not adopt the NP at the same time- provided they decide to include it in their assortment at all. Over time, the degree of market innovativeness wears off as people learn about the NP through advertising, word-of-mouth, or other means, which is likely to reduce demand. This suggests that NP performance is higher at retailers that adopt it earlier than their competitors. Second, we consider whether the retailer is a hard discounter or a mainstream retailer. Hard discounters have by a strong emphasis on PLs, small, austere stores, an unrelenting focus on price, and bare-bone product presentation in carton boxes. This may not be the best environment for an NP to prosper (Deleersnyder et al. 2007). Third, the overall economic context at the time the NP is introduced can influence its performance (Lamey et al. 2012). Consumers are known to be more risk averse in bad economic times. Thus, we expect that NPs perform better when retailers add them to their assortment under more favorable economic conditions.

Finally, several category characteristics are expected to make it more or less attractive for consumers to purchase NPs. Both category proliferation and category concentration are expected to diminish NP performance. If the retailer already carries a large number of sub-brands in the category, it is more difficult for the NP to stand out and influence brand choice. Similarly, it is generally more difficult for a new entrant to gain a foothold in highly-concentrated markets than in less-concentrated markets. As concentration increases, the importance of each brand to the total output will increase and firms are less likely to ignore the possible effect of any action by a rival. 
Apart from these retailer-specific variables, also some general (not retailer-specific) category characteristics will make it more or less attractive for consumers to purchase NPs. If a category is characterized by a higher proportion of shoppers who seek out a particular brand, this indicates greater relevance of brands and this would have a positive effect on NP performance. Furthermore, Steenkamp, van Heerde, and Geyskens (2010) show that consumers' beliefs about how difficult it is to make a good quality product in a particular category affects their perception of the quality gap between NBs and PLs, and their willingness to pay more for brands. These are conditions favorable to brands and their NPs. Finally, we control for purchase frequency (Steenkamp and Geyskens 2014).

\section{Method}

\subsection{Research setting}

Our research setting is the U.K., one of the biggest European grocery markets. It is the home market of Tesco, one of the world's largest and most sophisticated global retail chains. Other

leading retailers in the U.K. market include Asda, the most important wholly-owned subsidiary of Walmart, and Sainsbury's, one of the world's pioneers in PL development. The world's leading hard discounters, Germany's Aldi and Lidl, are also active in the U.K.

\subsection{Data}

Our main data source is six years of scanner panel data (from June 2004 until June 2010) covering grocery purchases of a representative sample of 15,000+ U.K. households, provided by Kantar Worldpanel. We augmented this database with consumer survey data and secondary data to operationalize the variables included in our research framework.

Identification of NPs. Category experts from Kantar Worldpanel identified 105 NPs launched in the U.K. market across 21 broad CPG categories with frequent NP activities during the period 
June 2005 to June 2008. ${ }^{1}$ For each of these 21 categories, the experts identified all NPs launched in the U.K. by one of the top 50 CPG manufacturers in the European grocery market (ranking based on the first full year of our screening period, source: Datamonitor). ${ }^{2}$ The categories cover a mix of foods, beverages, personal-care products, and household-care products.

Retailer NP adoption. From the panel data, we assessed whether (when) these NPs were adopted in the first year after their market launch by each of the 13 largest retail banners in the U.K. grocery business. These retailers collectively represent almost $80 \%$ of U.K. grocery sales, and they encompass hard discounters as well as mainstream retailers operating in different sizes. This resulted in a set of $105 \times 13=1,365$ NP-retailer combinations. In two instances, the retailer did not offer the specific category in its stores, leaving us with 1,363 observations for further analysis. On average, a retailer accepted $66 \%$ of the NPs, with hard discounter Lidl accepting the fewest (17\%), and Asda, Morrisons, Sainsbury’s, and Tesco accepting around 90\% of all NPs. Table 1 offers descriptive statistics on the 13 retail banners, along with NP acceptance and average performance at each retailer.

\section{--- Insert Table 1 about here ---}

\subsection{Measurement}

We operationalized NP performance as the NP's category volume share at the retailer in the first year after its listing at that retailer. Across the 13 retailers, the average market share of the NPs in the first year is $1.07 \%$, but considerable variation across retailers is observed in Table 1 . Hard

\footnotetext{
${ }^{1}$ The period between June 2004 and June 2005 is used to initialize certain variables. The data after June 2008 are still used to assess the post-introduction performance: we consider whether retailers accept the product within one year after market entry, and determine NP performance in the first year following a retailer's adoption.

2 To identify the NPs, the category experts identified those product lines/sub-brands for which the first purchase records occurred during the screening time window, and for which the EAN product description in the panel data identified a new benefit/attribute. In line with Gielens (2012), this allows us to abstract from promotional SKU additions and/or additions that reflect a mere SKU proliferation of the existing offerings (e.g., an additional fruit flavor in an existing yogurt line). As a validation, we cross-checked against the Product Launch Analytics database to identify CPG NPs. All our NPs were also identified by this source.
} 
discounters Aldi and Lidl show average first-year shares below .5\%, while NPs at Iceland obtain an average share of $2.94 \%$.

Table 2 provides the measures and sources for all variables. Both RBBE and the equity of the brand under which the NP was introduced were measured in an online consumer survey. The retailer and brand surveys were administered in 2009 among members of Kantar Worldpanel's online panel. Each retail banner was evaluated by at least 250 respondents, and each innovating brand by 45 to 50 respondents, conditional on their awareness of the retailer or brand. Table 3 reports means, standard deviations, and correlations for the variables in our NP performance equation. All time-varying variables are operationalized the year prior to the retailer's adoption (or, in case of non-adoption, the year prior to the right-censoring date), ${ }^{3}$ unless explicitly specified otherwise in Table 2.

\section{--- Insert Tables 2 and 3 about here ---}

\subsection{Model specification}

From the data, it is clear that not all 105 NPs are accepted by each of the 13 U.K. retailers in our sample. NP adoption by a retailer is likely to be a strategic choice driven by various motives, among which (potentially) the expected NP performance. If NPs that secure shelf presence at a particular retailer differ in important, but unobserved, characteristics from those that fail to obtain shelf presence, a problem of sample selection arises. Therefore, we simultaneously model NP performance at the retailer (=our focal outcome equation), conditional upon the retailer's decision to adopt the NP (= selection equation) with a selection model.

NP performance equation. Our NP performance equation has the following specification:

(1) $\ln \left(\frac{N P S_{i r}}{1-N P S_{i r}}\right)=\gamma_{0}+\sum_{k=1}^{3}\left(\gamma_{k} * U P S H O P_{i r k}\right)+\sum_{l=1}^{2}\left(\gamma_{l+3} * L O S H O P_{i r l}\right)$

\footnotetext{
${ }^{3}$ Determined as one year after the NP's initial launch in the U.K. market.
} 


$$
\begin{aligned}
& +\sum_{m=1}^{3}\left(\gamma_{m+5} * \text { STORECONTEXT }_{i r m}\right) \\
& +\sum_{k=1}^{3}\left(\gamma_{k+8} * \text { UPSHOP }_{i r k} * \text { RBBE }_{r}\right)+\sum_{l=1}^{2}\left(\gamma_{l+11} * \text { LOSHOP }_{i r l} * \text { RBBE }_{r}\right) \\
& +\sum_{k=1}^{3}\left(\gamma_{k+13} * \text { UPSHOP }_{i r k} * \text { PLS }_{i r}\right)+\sum_{l=1}^{2}\left(\gamma_{l+16} * \text { LOSHOP }_{i r l} * \text { PLS }_{i r}\right) \\
& +\sum_{k=1}^{3}\left(\gamma_{k+18} * \text { UPSHOP }_{i r k} * U_{\text {UI }}\right)+\sum_{l=1}^{2}\left(\gamma_{l+21} * \text { LOSHOP }_{i r l} * U N I Q_{i r}\right) \\
& +\gamma_{24} * \text { SPEED }_{i r}+\gamma_{25} * \text { DISC }_{r}+\gamma_{26} * E_{\text {CONOMY }} \\
& +\sum_{n=1}^{5}\left(\gamma_{n+26} * \text { CATCOVARIATES }_{i r n}\right)+\sum_{l=1}^{2}\left(\gamma_{l+31} * \text { COPULAS }_{i r l}\right)+\varepsilon_{1 i r},
\end{aligned}
$$

where $\ln \left(\frac{N P S_{i r}}{1-N P S_{i r}}\right)$ is the logistic transformation of the volume share of NP $i(i=1, . ., 105)$ at retailer $r(r=1, . ., 13)$ in the first year after the adoption at that retailer (NPS). Importantly, in calendar time, this time window can vary across retailers, as they did not all adopt the NP on the same day following its market introduction. We use the logistic transformation to account for the range constraint in market share. UPSHOP denotes the three upper-funnel shopper-marketing variables brand equity, brand advertising, and NP innovativeness, LOSHOP refers to the two lower-funnel shopper-marketing variables NP price premium and NP promotion intensity. STORECONTEXT denotes the three in-store context variables RBBE, PL share in the category (PLS), and uniqueness in the assortment (UNIQ). We further control for each retailer's speed of NP adoption (SPEED), whether the retailer is a hard discounter or not (DISC), and ECONOMY reflects the state of the economy. The five category variables indicated by CATCOVARIATES are category proliferation and category concentration at the retailer, as well as the general category characteristics brand loyalty, difficulty of making the category, and purchase frequency. Finally, COPULAS refers to the two copula-based variables to control for endogeneity in the lower-funnel shopper-marketing activities (see below).

Adoption equation. While the focus of this paper is not on why some retailers adopt certain NPs while others do not, failure to control for this can result in biased parameter estimates in our 
focal model. As such, we estimate the likelihood that retailer $r(r=1, . ., 13)$ adopts NP $i(i=1, . ., 105)$ in the first year after the national launch with the following probit model:

(2) ADOPT $_{i r}^{*}=\beta_{0}+\sum_{k=1}^{3}\left(\beta_{k} *\right.$ UPSHOP $\left._{\text {irk }}\right)+\sum_{l=1}^{2}\left(\beta_{l+3} *\right.$ LOSHOP $\left._{\text {irl }}\right)+\sum_{m=1}^{3}\left(\beta_{m+5} *\right.$ STORECONTEXT $\left._{\text {irm }}\right)$

$$
\begin{aligned}
& +\beta_{9} * \text { SPEED }_{i r}+\beta_{10} * \text { DISC }_{r}+\beta_{11} * \text { ECONOMY }_{i r} \\
& +\sum_{n=1}^{5}\left(\beta_{n+11} * \text { CATCOVARIATES }_{i r n}\right)+\sum_{o=1}^{4}\left(\beta_{o+16} * \text { MCONTROL }_{i r o}\right)+\varepsilon_{2 i r}
\end{aligned}
$$

where $\mathrm{ADOPT}_{\mathrm{ir}}=1$ if $\mathrm{ADOPT}^{*} \mathrm{ir}>0$ and zero otherwise. The factors that increase (decrease) NP performance at the retailer are likely to also affect a retailer's incentive to accept the NP into its assortment. Accordingly, the same drivers of NP performance appear in the NP adoption equation. Importantly, post-adoption advertising, price, and promotion variables are not yet known at the time of the adoption decision (and NP price and promotion are never observed in case of rejection). We develop proxies for these variables (see below). Moreover, MCONTROL contains four manufacturer variables that are expected to drive retailers' decision to adopt NPs, but not necessarily NP performance at that retailer. ${ }^{4}$ Given that shoppers are typically familiar with the brand under which a product is sold, but much less knowledgeable about the manufacturer behind these products, ${ }^{5}$ we make use of four manufacturer-related variables: their overall innovativeness, their power relative to the retailer - both within the category and across categories - and the price premium commanded by the mother brand which signals the manufacturer brand's potential to contribute to the retailer's profit. ${ }^{6}$ We add these manufacturer variables only to the adoption equation. The other variables are as defined before.

\footnotetext{
${ }^{4}$ The exclusion restrictions, while not absolutely necessary, are useful for identification purposes (Johnston and Dinardo 1997, p. 450). When these variables are also added to the NP performance equation, none of our key findings are affected. Moreover, these variables are insignificant in this equation, providing empirical support for their exclusion.

5 This is consistent with the idea that NBs in CPG follow mostly a 'house of brands' rather than a 'branded house' strategy. Our data confirms that all manufacturers in our sample own and market multiple brands.

${ }^{6}$ Ideally, our adoption equation would also include profit-related drivers like slotting allowances and NP margin information. Unfortunately, this information is notoriously hard to get for any retailer, let alone for 13 retail banners.
} 


\subsection{Model estimation}

We estimate our model with a joint Maximum Likelihood estimation, which has been shown to be more efficient than the more traditional two-stage estimation (Breen 1996). ${ }^{7}$ To allow for the possibility that unobserved characteristics may affect both retailer NP adoption and performance, no restrictions are imposed on the correlation between the error terms $\varepsilon_{1 i r}$ and $\varepsilon_{2 i r}$. In estimating our model, we take into account several additional issues. First, to limit the influence of outlying observations in our analysis and to reduce skewness, we ln-transform all continuous predictors ${ }^{8}$, and mean-center these variables for ease of interpretation. We use effects coding for the dummy variables NP innovativeness and hard discounter.

Second, even though we focus on several shopper-marketing instruments, there may be other shopper-marketing activities (such as aisle and display-management strategies) that are not explicitly measured, but which could have important effects on the NP performance at the retailer. To control for potential within-retailer correlations across the different NPs, we employ clusterrobust standard errors, in which the error terms are allowed to be correlated across the NPs within a retail banner.

Third, we develop proxies for the not-yet-observed/missing values for post-adoption advertising, price, and promotion. The fraction of brand advertising in total mother-brand sales in the year prior to adoption is used to signal the manufacturer's support for and investment in its NPs after launch. The price premium for the NP prior to adoption is measured as the average price of the NP at all other adopting retailers relative to the weighted national category price (with the

\footnotetext{
7 A condition number of 14.7, well below the proposed threshold of 20 (Leung and Yu 1996), indicates that our model does not suffer from collinearity problems between the inverse Mills ratio and the outcome regressors. Thus, a sample-selection specification is appropriate.

${ }^{8}$ A formal joint skewness test (Mardia's mSkewness) reveals that the independent continuous variables in the NP performance equation are highly skewed $(p<.01)$, with also 14 out of the 16 individual skewness tests significant at $p$ $<.10$. For variables that took the value of zero in our sample (NP promotion intensity, category PLS and uniqueness in assortment), a value of one was added to every observation prior to the $\ln$-transformation.
} 
respective brands' value share as the weight). This measure captures whether the focal NP is relatively expensive compared to current category offerings in the market. We infer the promotional intensity for the NP based on the promotional intensity the mother brand received in the year prior to NP adoption at this retailer. Furthermore, we measure uniqueness in the assortment as well as our purchase frequency and state of economy variable one year prior to adoption (instead of the post introduction variant included in the outcome equation).

Fourth, the retailer may a priori have certain expectations about the NP at its stores, and act accordingly. As a result, the proposed lower-funnel shopper-marketing drivers may not be exogenously determined. To account for this, we adopt the instrument-free Gaussian copulas approach (Park and Gupta 2012). This approach is especially useful when it is hard to find good instruments, as in our case. We add two copula-based control variables linked to the two lowerfunnel shopper-marketing activities that are measured at the retailer level (i.e., NP price premium and NP promotion intensity) to the performance equation, operationalized as follows:

$$
\operatorname{COPULAS}_{l}=\Phi^{-1}\left(\mathrm{H}_{\left.\left(\mathrm{LOSHOP}_{l}\right)\right)}\right.
$$

where $\Phi^{-1}$ is the inverse of the cumulative normal distribution function, and $\mathrm{H}($.$) the empirical$ distribution of the respective shopper-marketing variable. For identification, it is necessary that each variable is non-normally distributed. This was confirmed by a Shapiro-Wilk test for both lower-funnel shopper-marketing variable $(p$ 's $<.10)$. Only retailer promotion intensity for the NP is found to be endogenous $(p<.01)$.

Finally, instead of retaining all 15 interactions specified in Equation 1, which would lead to unstable results and multicollinearity, we estimate a trimmed model in which only interactions that are significant at $p<.20$ are retained (see Steenkamp and Geyskens 2014 for a similar practice). 


\section{Results}

\subsection{Adoption equation}

The maximum VIF factor for this equation is 4.25. This suggests multicollinearity is not a major issue. We obtain a hit rate of $81.66 \%$, which is significantly better than chance $\left(55 \%=\alpha^{2}+(1-\right.$ $\alpha)^{2}$, with $\alpha=66 \%$ ). The parameter estimates are shown in Table 4 . A retailer is more likely to include the NP in its assortment if it is a breakthrough NP $\left(\beta_{3}=.195, p<.01\right)$ and when they come with more promotional support $\left(\beta_{5}=2.049, p<.01\right)$. The retail context also drives NP adoption decisions. High RBBE retailers are more likely to adopt an NP compared to low RBBE retailers $\left(\beta_{6}=3.937, p<.01\right)$, while more unique products that stand out in package size and/or brand name from other assortment offerings are less likely to gain acceptance among retailers $\left(\beta_{8}=-3.213, p<\right.$ $.01)$, suggesting that retailers strive for cohesion in their assortments. Further, NPs are less likely to gain acceptance at limited-assortment hard discounters $\left(\beta_{10}=-.541, p<.05\right)$, and in highly concentrated categories $\left(\beta_{13}=-1.136, p<.01\right)$. Thus, category concentration not only acts as barrier to entry in an industry, but also at the micro level of individual retailers. Adoption of branded NPs is also more likely in categories where consumers believe it is difficult to make a quality product $\left(\beta_{15}=4.901, p<.01\right)$.

Finally, all four manufacturer variables are found to drive retailer NP adoption, even though they are unrelated to consumer NP acceptance (see footnote 4). An NP is more likely to be included in the assortment of a retailer if the NP is introduced by a manufacturer that has a history of frequent NP introductions $\left(\beta_{17}=.549, p<.01\right)$, if the manufacturer has considerable power over the retailer - both across categories $\left(\beta_{18}=1.357, p<.01\right)$ and within the category in question $\left(\beta_{19}\right.$ $=.059, p<.10)-$ and if a higher price premium can be charged for the NP at that retailer $\left(\beta_{20}=\right.$ $.271, p<.05)$, The hit rate and the face validity of the parameter estimates provide support for the validity of the adoption equation. 


\subsection{Model selection}

We build our model by successively adding blocks of predictors as specified in Equation 1 (the selection equation remains the same). Table 5 provides the results of the incremental model building approach. As can be seen, all blocks of variables contribute to the explanatory power of NP performance. Thus, our discussion will focus on Model M6.

The maximum VIF factor for Model M6 is 6.52. The error-correlation between $\varepsilon_{1 i r}$ and $\varepsilon_{2 i r}$ is negative and significant $(\rho=-.164 ; p<.05)$, which underscores the importance of using a selection model in our modeling effort. Its negative sign implies that, on average, the remaining unobserved factors (e.g., slotting allowances or trade promotions that convinced an initially reluctant retailer) may have an opposite effect on NP performance once offered in its stores. ${ }^{9}$ --- Insert Table 5 about here ---

\subsection{Drivers of retailer NP performance}

The parameter estimates for Model M6 are reported in Table 6. However, the estimates per se do not give a good idea about the substantive impact of the various drivers on NP share at a retailer because they are measured on different scales. To get a sense of their substantive impact, we calculate for each variable in our NP performance equation how much the NP category share at the retailer will change (in percentage points) if this variable goes from one standard deviation below its mean to one standard deviation above its mean (Table 7). ${ }^{10}$ For the dichotomous variables NP

\footnotetext{
${ }^{9}$ Many of such unobserved factors may be at play and only their net effect is reflected in $\rho$ (some other factors may well have a positive association). Clearly, this resulting net effect of the not-included factors will vary with the set of included factors (several of which turn out to have a common effect across the selection and outcome equation). ${ }^{10}$ To illustrate, we show how we arrive at these results for brand equity. We calculate the logit-transformed NP retailer share for brand equity (with a standard deviation for the 1 -transformed variable of .073) at one standard deviation below zero (given mean centering) as $-5.214+.909 *(-.073)=-5.280$ with -5.214 the intercept $\gamma_{0}$ and .909 the parameter estimate $\gamma_{1}$ for brand equity in Table 6. The resulting NP retailer share, after reconversion, is $.51 \%$. We repeat these calculations at one standard deviations above the mean as $-5.214+.909 *(.073)=-5.148$, resulting in an NP retailer share of $.58 \%$. The difference (in percentage points) for a variation of one standard deviation on both sides of the variable's mean is $.58 \%-.51 \%=+.07 \%$.
} 
innovativeness and hard discounter, we report the market share effect of the logical variation in the variable (breakthrough NP/hard discounter versus incremental NP/other store format). To determine the NP retailer shares, all other variables are fixed at their mean level (or zero for effectcoded dummy variables).

We will now turn to a discussion of the results. We will structure our overview around the four research questions identified in Section 1.

--- Insert Tables 6 and 7 about here ---

\subsubsection{How important is shopper marketing in determining NP performance at the retailer?}

The first question concerns the importance of shopper marketing in the context of NP performance. Is it truly that important? The answer is a definite yes. We find that collectively, shopper-marketing efforts related to the NP explain $26.78 \%$ of the variance in NP performance (i.e., 53.08 - 26.30; Table 5). If we next allow for the idea that the idiosyncratic in-store shopper context affects the effectiveness of shopper-marketing instruments, this percentage further increases to $29.22 \%$.

5.3.2 What is the relative importance of the set of upper-funnel vs. lower-funnel shoppermarketing variables?

The second question is about the relative importance of the set of upper-funnel (market-level) shopper-marketing variables versus the set of retailer-specific, lower-funnel shopper-marketing variables in explaining NP success. Which group of factors is more important? Aggregated across the individual main effects reported in Table 7, lower-funnel marketing actions, which ultimately vary by retailer and that are the outcome of intense retailer-manufacturer negotiations, have more than three times the impact on NP performance than the upper-funnel marketing actions used by manufacturers to affect consumers early in the NP purchase cycle. 
5.3.3 What is the substantive impact of the different shopper-marketing variables on NP performance?

What can we say about the importance of individual shopper-marketing instruments on NP success? Which are the key drivers? We propose that a driver that has a relative market-share effect of one standard deviation around the mean of at least $25 \%$ might be considered a strong driver, while a driver that has a relative market-share effect of at least $10 \%$ might be considered a medium driver. We classify drivers with an effect below $10 \%$ as small. The average category share of an NP at a retailer is $1.07 \%$ (Table 1). This means that effects in Table 7 that give rise to an absolute market share change of at least $.27 \%(.11 \%)$ can be interpreted as large (medium).

We find that two shopper-marketing variables have a large effect, using this classification scheme: NP price premium $\left(\gamma_{4}=-.835, p<.01\right)$ and NP promotion intensity $\left(\gamma_{5}=2.386, p<.01\right)$. High-priced NPs achieve a market share that is on average .51 percentage points lower than lowpriced NPs. ${ }^{11}$ Highly promoted NPs achieve a market share that is $.33 \%$ higher than NPs that received little promotional support at the retailer in question.

The main effects of the upper-funnel shopper-marketing activities are all significant: brand equity $\left(\gamma_{1}=.909, p<.05\right)$, brand advertising $\left(\gamma_{2}=.054, p<.01\right)$, and NP innovativeness $\left(\gamma_{3}=.100\right.$, $p<.05)$. However, the magnitude of their impact is medium or less. NPs of heavily advertised brands capture a $.13 \%$ higher share than those that are not heavily advertised, while the market share achieved by breakthrough NPs is, on average, .11\% higher than that of incremental NPs. The main effect of brand equity is small ( $\Delta$ market share $=.07 \%)$.

We further find support for the main effect of the two category-context variables in our research framework (Figure 1), but not for the overall retail-banner context. NP performance is

\footnotetext{
${ }^{11}$ Unless indicated otherwise, in the remainder of the paper when we talk about percentages, we refer to percentage points.
} 
lower in categories where the retailer's own PL is stronger $\left(\gamma_{7}=-.825, p<.01\right)$ and if the NP is more unique in the assortment at the retailer $\left(\gamma_{8}=-3.138, p<.01\right)$. Both effects (uniqueness: $\Delta$ market share $=-.21 \%$; category PL share: $\Delta=-.13 \%$ ) can be classified as medium in magnitude size. However, the more important role of the store-context variables is in moderating the effect of shopper-marketing instruments on NP performance, to which we now turn.

\subsubsection{To what extent do the effects of the various shopper-marketing variables differ according to} the store context in which the NP is sold?

In line with Greene (2010), we focus on the significance of the relevant product terms in Table $6 .{ }^{12}$ The substantial number of significant interactions indicates that the effectiveness of shoppermarketing activities indeed depends on the store context. Table 7 (right-hand side) provides information on the substantive importance of the interactions for two levels (one standard deviation above and below the mean) of the moderating variables RBBE, category PL share and NP uniqueness in the assortment at the retailer.

Below, we focus on interactions that are associated with a medium or large effect size (i.e., a difference in market share between high and low values of the store-context variable in question of at least .11 percentage points). We graphically depict all significant interactions in Figure 2 for the upper-funnel shopper-marketing variables, and in Figure 3 for the lower-funnel shoppermarketing variables, where we show the impact of a gradual increase in the shopper-marketing instruments across the full range observed in our data. ${ }^{13}$ Note that the lower importance of the upper-funnel marketing activities is already reflected in the different scaling that we adopted for Figure 2 versus Figure 3.

--- Insert Figures 2 and 3 about here ---

\footnotetext{
12 Thus, we do not focus on the significance of changes in the partial effects, since these can be seen as an artifact of our non-linear functional form (Greene 2010, p. 295).

${ }^{13}$ In Table 7 and Figures 2 and 3, the other continuous variables are held at their mean level (or zero for effect-coded dummy variables).
} 
Upper-funnel shopper-marketing variables. The equity of the brand under which the NP is introduced plays a considerably larger role at high RBBE retailers than at low RBBE retailers $(\Delta$ market share $=.12 \%$ ). See Figure 2 (panel A.1) for the graph. We find further that the effect of brand equity on NP performance varies systematically in function of the share of the retailer's PL $(\Delta=.16 \%)$. As shown in Figure 2 (panel B.1), if the retailer has been able to achieve a strong position for its store brand in the category, brand equity does not really contribute to NP success. However, in categories where the retailer's own brand is in a weak position, brand equity has an appreciable effect on NP performance. Combined, this means that the brand matters the most at highly regarded retailers and in product categories where a retailer has not achieved a strong position with its own brand.

The effect of NP innovativeness on its performance is amplified at high RBBE retailers $(\Delta=$ $.19 \%$ ). As Figure 2 (Panel A.3) shows, for low RBBE retailers, NP innovativeness matters relatively little. Any new product already might render the in-store shopping context a little more appealing. However, for high RBBE retailers, a breakthrough NP is necessary to stand out against a competitive context of a strong assortment and a reputable store brand. In addition, NP assortment uniqueness moderates the positive effect of NP innovativeness on its performance $(\Delta=$ $.23 \%$ ). As visualized in Figure 2 (panel C.1), the positive effect of NP innovativeness only holds for NPs that are low on uniqueness in the assortment. For NPs high on assortment uniqueness, in contrast, the breakthrough value of the product does not result in a higher NP performance. This is consistent with consumer's familiarity-safety association documented in Zajonc (1984): people generally prefer previously seen, familiar stimuli over novel ones and hence, more familiar NP traits will make it less risky for consumers to try out breakthrough NPs in such retailer assortments. 
Lower-funnel shopper-marketing variables. The negative effect of NP price premium on its performance is even stronger at high $\mathrm{RBBE}$ retailers $(\Delta=.12 \%)$ - see Figure 3 (panel A.1). Hence, the ability of the manufacturer to negotiate the price of the NP is of greater importance at high RBBE retailers. Alternatively, while promotion intensity always improves NP performance, it is significantly less effective at high RBBE retailers (see Figure 3, panel A.2). In fact, this is the strongest moderating effect of them all. Compared to running price promotions in high RBBE retailers, doing the same price promotion in a low RBBE retailer is associated with a market share that is, on average, $.41 \%$ higher.

PL share moderates the effectiveness of promotion support for the NP $(\Delta=.12 \%)$. If the retailer's PL is strong in the category, and supporting the NP with heavy promotion is even more important. This is graphically reflected in the steeper slopes for NP promotion intensity (upward) in high PL share categories (see Figure 3, panel B.2). This finding corroborates Pauwels and Srinivasan (2004), who show that the presence of a strong PL at the retailer increases consumers' sensitivity to price-related instruments.

\subsubsection{Effect of covariates}

Finally, we briefly turn to the role of the covariates in NP performance. One covariate clearly stands out - within-retailer category proliferation. In categories with many (sub)brands, expected NP share is $.57 \%$ lower than in categories with a more limited assortment. Three other covariates have a medium effect size. NP performance is lower at hard discounters $(\Delta=-.19 \%)$ and in more concentrated categories ( $\Delta=-.20 \%$ ), while NP performance is higher in categories that according to consumers are difficult to make $(\Delta=.21 \%)$.

\section{Robustness Checks}

We perform a series of robustness tests to ensure the stability of our results, which we summarize in Table 8. 
Sensitivity to the time window. In our analysis, we evaluated retailer NP performance over a time period of one year following the NP adoption by the retailer. As a robustness check, we reestimated our models with the retailer NP performance metric evaluated over a shorter and longer time period of, respectively, 9 and 18 months after retailer adoption.

Alternative estimation method. To evaluate the sensitivity of our results to our estimation method, we re-estimated the system with the more traditional two-stage estimation approach, instead of the adopted joint Maximum Likelihood estimation advocated by Breen (1996).

Alternative clustering. Tesco operates four separate chain formats in the U.K. market: Tesco (regular), Tesco Express, Tesco Extra, and Tesco Metro. In our analysis, we treat these four Tesco formats as separate retail banners, since they vary considerably on multiple dimensions such as store size, perceived RBBE, retailer NP adoption, and average NP performance at the retailer (see Table 1). Nonetheless, there may be a closer relationship in NP acceptance and NP performance among the Tesco formats than with other U.K. retail chains. Therefore, we also estimated the model with an alternative error structure, i.e. where we allow the error terms of all Tesco observations to be correlated with one another (irrespective of the specific Tesco banner), while those of the non-Tesco observations remain correlated within their respective banner (hence, allowing for 10 rather than 13 clusters).

Alternative transformation on the $D V$. Instead of using the logit transformation on the NP share metric, we re-estimated our NP performance equation with the ln-transformed NP share as dependent variable (resulting in a log-log model specification).

Controlling for retailer NP activity. We evaluated if NP performance is worse when the retailer launches (more) NPs under its own store brand in the same time period. Data on retailer NP activity was acquired through Product Launch Analytics. It was operationalized as the number of new PL sub-brands in the category at the retailer in the year after the focal NP was added to the 
assortment relative to the number of PL sub-brands available at the retailer in that year. This variable was added to the performance equation.

Controlling for seasonality. To control for potential seasonality that may affect both NP adoption and subsequent performance, we re-estimated our models with three additional quarterly dummies (quarter dummy $=1$ if the retailer adopted the NP within that quarter, 0 otherwise).

Controlling for other retail formats. Besides controlling for the hard-discounter store format, we added an additional format dummy to our models, indicating whether the retail banner is a convenience store. The only convenience retail banner in our sample according to PlanetRetail is Tesco Express.

--- Insert Table 8 about here ---

Our results are very stable, as Table 8 details. For the five shopper-marketing main effects, the findings replicate in 38 of the 40 instances. Similarly, all 24 main effects of the three store-context variables are replicated across the eight robustness checks. With respect to the interactions between the shopper-marketing instruments and the store context, our results are robust across 78 out of 80 instances. Moreover, also the effects of our covariates were very robust, with the harddiscounter dummy losing its significance in only one instance and the effects of all others consistent across all validations.

\section{Discussion}

Shopper marketing has recently gained prominence as a more comprehensive way to understand and influence consumers along their path-to-purchase. In this paper, we examine the role of shopper-marketing activities in the performance of NPs introduced by NB manufacturers at the level of individual retailers. We distinguish between upper-funnel marketing instruments that influence consumers early in the NP shopping cycle (brand equity, brand advertising, NP innovativeness) and lower-funnel, retailer-specific, instruments that affect consumers later in the 
purchase cycle right before or during the actual shopping trip (NP price premium and NP promotion intensity). Consistent with shopper-marketing's recognition of the importance of the shopping context in which purchases take place, we allow for contingency effects of the overall retailer-wide store context $(\mathrm{RBBE})$ and the retailer category-specific context (category PL share and NP uniqueness in the assortment) on the effects of the shopper-marketing factors.

We summarize our findings in Table 9. We classify the magnitude of each factor as large, medium, or small, based on the analysis of their substantive importance as provided in Table 7 , using the classification scheme proposed above. We now turn to managerial implications of our results.

--- Insert Table 9 about here ---

\subsection{Managerial implications}

Our study has two main findings of overarching managerial relevance. First, brand managers need to take a comprehensive shopper-marketing view when it comes to introducing NPs. They need to consider the entire path-to-purchase. Shopper environments differ between retailers and this has a profound impact on NP success. NP marketing plans at the market level that fail to take this into account will be deficient. Second, we show that the pendulum has shifted decisively from the manufacturer to the retailer as manufacturers are not fully in control of what happens with their NPs in store. Marketing-mix instruments that are a shared retailer-manufacturer responsibility have at least three times the impact of the set of factors that are still under the manufacturer's exclusive control. When it comes to NP success, the lifeblood of CPG companies, lower-funnel marketing actions targeting shoppers directly at the point-of-purchase ultimately decide your fate.

That does not mean that manufacturers are powerless, but rather that they should work ever harder to collaborate with retailers and push the store specific shopper-marketing instruments in a favorable direction. The way forward is information sharing and the development of NP marketing 
programs tailored to individual retailers. Shankar et al. (2011, p. S37) note that retailers believe that it is primarily the manufacturers' responsibility to bring shopper-marketing insights to the planning table. Our study provides such pertinent insights. It highlights the key importance of NP pricing and promotion. Assuming that if a retailer adopts an NP, it has an interest in making it successful (otherwise, why bother to do it in the first place), the manufacturer can work with the retailer in setting adequate prices and designing promotion calendars and programs that maximize the pass-through, e.g., by tying consumer promotions to trade promotions. The manufacturer can customize the shopper-marketing insights by taking into account the retailer's RBBE. If the manufacturer does not have information on RBBE, it is easy to collect with our measurement instrument. The manufacturer could consider allocating more of its promotion budget to low RBBE retailers, given the very strong effect of promotions at these retailers. Conversely, it could offer the NP at a lower price at high RBBE retailers - and negotiate that these retailers passthrough the lower price to their shoppers. Table 9 provides suggestions for tailoring your NP marketing program in function of the within-retailer category context.

However, not all news is bleak for brand manufacturers. There is a silver lining to our findings - more specifically five silver linings. First, it has been ever more difficult for CPG firms to come up with breakthrough NPs (Sorescu and Spanjol 2008). While we find that breakthrough NPs generate on average a higher market share $(+.11 \%)$ than incremental NPs, the effect is modest compared to other factors, and even smaller than the effect of advertising (+.13\%). Especially in assortments where NPs are more unique, incremental NPs do hardly worse than breakthrough NPs. So incremental NPs continue to offer something new and different.

Second, hard discounters are on the rise in Western countries. NB manufacturers are increasingly interested to sell through this retail channel but are uncertain whether sales will make it worth their while (Deleersnyder and Koll 2012). Note that NPs perform worse at hard 
discounters than at other retailers. Hence, if the challenge is to be more represented in the hard discounter assortment, we advise manufacturers to push first their mature brands rather than their NPs at those outlets, which are more likely to create a win-win situation for both channel parties (Deleersnyder et al. 2007).

A third silver lining is the role of consumer beliefs about the difficulty of making high quality products in a given category. While such consumer beliefs are not easy to change, it is worth the effort given that 1) the effect is considerable (+.21\%) and 2) investments in changing such perceptions can be leveraged across all retailers as it is distinct from any particular retailer. One way to enhance this belief is through advertising that stresses the amount of experience and knowledge that goes into producing good-quality products. For example, the Dutch beer manufacturer Grolsch used to run TV commercials showing the amount of craftsmanship required in many different professions (e.g., making musical instruments), and by projection, in brewing good beer.

Fourth, Lamey et al. (2012) recommend that brand manufacturers ramp up their NP activity in recessions to arrest the growth of PLs, but find that they do the opposite. Two reasons for this are the uncertainty whether retailers might be willing to adopt them and whether shoppers are inclined to try out something new in tough times. We find no strong evidence for either. The effect of the state of the economy on the likelihood of adopting NPs is not significant (Table 4) and its effect on NP performance, while significant, is below the cutoff of even a medium effect size $(+.05 \%)$. This finding is especially noteworthy as our sample includes the Great Recession that hit the U.K. from March 2008 through June 2009.

Finally, while the manufacturer has limited control over NP performance, performance can only transpire if the retailer decides to adopt the NP. Table 4 shows that the manufacturer has influence on the retailer's adoption decision. It can use its power in the market and against the 
retailer as well as its record of NP launches to persuade the retailer to adopt the product.

\subsection{Limitations and future research}

Our study has several limitations that offer interesting avenues for future research. First, while we cast a fairly wide net in terms of shopper-marketing variables, there are other variables that could be considered (Shankar 2011). Future research could enrich our understanding of retailer-specific NP performance by considering shelf layout and facings, store layout, atmospherics, navigation, and especially in-store promotion support in the form of displays, features and other type of merchandising, while also taking into account whether, e.g., slotting allowances were used to persuade the retailer to list the NP. Second, the shopper-marketing concept acknowledges the importance of shopping trip motivations and influences, and post-purchase evaluation and recommendation. This requires other research approaches like experiments, surveys, and in-store observations. Third, in our work, RBBE was measured at a single point in time. There is some evidence that RBBE ratings are indeed rather stable over time. Since 2007, branding consultancy Brand Finance estimates a brand's strength annually using a balanced score card approach. It reports for the period 2007-2009 ratings $\mathrm{AA}+, \mathrm{AA}+, \mathrm{AA}+$ for Tesco, and $\mathrm{AA}-, \mathrm{A}+$, and $\mathrm{A}+$ for Asda. Yet, we acknowledge that RBBE may evolve over time as a function of retailers' strategic decisions. The same applies to brand equity. Future research could replace our static measures with annual updates.

Fourth, all stores of a given banner tend to use similar marketing and merchandising strategies, and offer the same, or nearly the same, variety of products. We model NP adoption by the retailer as a binary choice (yes/no) at the level of the retail banner. In this context, it is important to note that even though retailer Tesco operates in the U.K. market with four different formats (Tesco, Tesco Express, Tesco Extra and Tesco Metro), we treated these as separate banners in our analysis, given that some NPs are not adopted in all Tesco banners (or not at the 
same time). Future research could examine if and when NP roll-out differs across stores from the same banner, making the individual stores (rather than individual banners) the unit of analysis. Controlling for region-specific economic indicators rather than the current national-level indicator would then be called for in such an individual store setting. In addition, we implicitly assumed that the observed absence of an NP at a banner is due to the retailer refusing to accept the NP, which is in line with the dominant view in the literature (van Everdingen et al. 2011). Still, the observed absence might also be due to manufacturers refusing to offer the product to a given retailer.

In this paper, we have adopted the perspective of the brand manufacturer. We examined which factors drive NP success at individual retailers. Still, our performance metric is not informative on the sources of the NP's sales at the retailer. These may come at the expense of the mother brand or other brands owned by the manufacturer (undesirable for the manufacturer), at the expense of the retailer's PL (undesirable for the retailer), at the expense of brands of other NB firms (desirable for the manufacturer and (un)desirable for the retailer, dependent on profit margins), and/or from category expansion (desirable for both parties). Future research should examine alternative NP performance measures at the level of the retailer to identify the source of the NPs' sales. Dependent on the results, this may increase (or hamper) the strategic alignment between the brand manufacturer and the retailer advocated by Shankar et al. (2011).

From the retailer's point of view, an equally - if not more - important question is the role of the NP in growing its national share of the category. That is an important complementary topic worthy of more research. Our context does not allow us to study this issue as the average market share of an NP at a retailer is only $1.07 \%$. While such a low share is not at all atypical in the mature CPG industry with its many sub-brands and SKUs per category, it is too small to reliably identify any category market share expansion for the retailer. 


\section{References}

Ailawadi, Kusum L. and Bari Harlam (2009), "Retailer Promotion Pass-Through: A Measure, Its Magnitude, and Its Determinants," Marketing Science, 28 (Summer), 782-791.

------- and Kevin L. Keller (2004), "Understanding Retail Branding: Conceptual Insights and Research Priorities," Journal of Retailing, 80 (December), 331-342.

------, Norm Borin, and Paul W. Farris (1995), "Market Power and Performance: A Cross-Industry Analysis of Manufacturers and Retailers," Journal of Retailing, 71 (Autumn), 211-248.

Ataman, M. Berk, Carl F. Mela, and Harald J. van Heerde (2008), "Building Brands," Marketing Science, 27 (Winter), 1036-1054.

Breen, Richard (1996), Regression Models - Censored, Sample Selected, or Truncated Data, London/New Delhi: Sage Publications.

Cleeren, Kathleen, Harald J. van Heerde, and Marnik G. Dekimpe (2013), "Rising from the Ashes: How Brands and Categories Can Overcome Product-Harm Crises," Journal of Marketing, 77 (March), 58-77.

Corstjens, Judith and Marcel Corstjens (1995), Store Wars: The Battle for Mindspace and Shelfspace, Chicester: Wiley.

Court, David Dave Elzinga, Susan Mulder, and Ole Jørgen Vetv (2009), "The Consumer Decision Journey," McKinsey Quarterly, June. http://www.mckinsey.com/businessfunctions/marketing-and-sales/our-insights/the-consumer-decision-journey.

Deleersnyder, Barbara, Marnik G. Dekimpe, Jan-Benedict E.M. Steenkamp, and Oliver Koll (2007), "Win-Win Strategies at Discount Stores," Journal of Retailing and Consumer Services, 14 (5), 309-318.

------- and Oliver Koll (2012), "National Brands at Discount Stores: A Winning Proposition?" European Journal of Marketing, 46 (9), 1150-1170.

Dhar, Sanjay K. and Stephen J. Hoch (1997), "Why Store Brand Penetration Varies by Retailer," Marketing Science, 16 (Summer), 208-227.

Erdem, Tülin (1998), "An Empirical Analysis of Umbrella Branding," Journal of Marketing Research, 35 (August), 339-351.

Ernst\&Young/ACNielsen (2000), New Product Introduction, Successful Innovation/Failure: A Fragile Boundary, Paris: Ernst\&Young Global Client Consulting.

Gielens, Katrijn (2012), "New Products: The Antidote to Private Label Growth?” Journal of Marketing Research, 49 (June), 408-423.

------ and Jan-Benedict E.M. Steenkamp (2007), "Drivers of Consumer Acceptance of New Packaged Goods: An Investigation Across Products and Countries," International Journal of Research in Marketing, 24 (June), 97-111.

Greene, William H. (2010), "Testing Hypotheses about Interaction Terms in Nonlinear Models," Economic Letters, 107 (May), 291-296.

Guyt, Jonne Y. and Els Gijsbrechts (2014), "Take Turns or March in Sync? The Impact of the National Brand Promotion Calendar on Manufacturer and Retailer Performance," Journal of Marketing Research, 51 (December), 753-772.

Heeler, Roger M., Michael J. Kearney, and Bruce J. Mehaffey (1973), "Modeling Supermarket Product Selection," Journal of Marketing Research, 10 (February), 34-37.

Johnston, Jack and John Dinardo (1997), Econometric Methods, New York, NY: McGraw Hill $\mathrm{Co}, 4^{\text {th }} \mathrm{ed}$.

Klein, Benjamin and Keith B. Leffler (1981), "The Role of Market Forces in Assuring Contractual Performance," Journal of Political Economy, 89 (4), 615-641. 
Kumar, Nirmalya, and Jan-Benedict E.M. Steenkamp (2007), Private Label Strategy: How to Meet the Store Brand Challenge, Cambridge, MA: Harvard Business School Press.

Lamey, Lien, Barbara Deleersnyder, Marnik G. Dekimpe, and Jan-Benedict E.M. Steenkamp (2007), "How Business Cycles Contribute to Private-Label Success: Evidence from the U.S. and Europe," Journal of Marketing, 71 (January), 1-15.

------, ------, Jan-Benedict E.M. Steenkamp, and Marnik G. Dekimpe (2012), "The Effect of Business-Cycle Fluctuations on Private-Label Share: What Has Marketing Conduct Got to Do With It?" Journal of Marketing, 76 (January), 1-19.

Lehmann, Donald R., Kevin L. Keller, and John U. Farley (2008), “The Structure of Survey-Based Brand Metrics," Journal of International Marketing, 16 (December), 29-56.

Lemmens, Aurélie, Christophe Croux, and Marnik G. Dekimpe (2007), "Consumer Confidence in Europe: United in Diversity?" International Journal of Research in Marketing, 24 (June), 113-127.

Lemon, Katherine N. and Peter C. Verhoef (2016), "Understanding Customer Experience Throughout the Customer Journey," Journal of Marketing, 80 (November), 69-96.

Leung, Siu F. and Shihti Yu (1996), "On the Choice Between Sample Selection and Two-Part Models," Journal of Econometrics, 72 (May-June), 197-229.

Morgan, Neil A. and Lopo L. Rego (2009), "Brand Portfolio Strategy and Firm Performance," Journal of Marketing, 73 (1), 59-74.

Nijs, Vincent R., Shuba Srinivasan, and Koen Pauwels (2007), "Retail-Price Drivers and Retailer Profits," Marketing Science, 24 (July-August), 473-487.

Park, Sungho and Sachin Gupta (2012), "Handling Endogenous Regressors by Joint Estimation Using Copulas," Marketing Science, 31 (July-August), 567-586.

Pauwels, Koen and Shuba Srinivasan (2004), "Who Benefits from Store Brand Entry?" Marketing Science, 23 (Summer), 364-390.

Rubinson, Joel (2010), "Marketing from the Other End of the Funnel," presentation at the MSI Conference, June.

Shankar, Venkatesh (2011), Shopper Marketing, Cambridge (MA): Marketing Science Institute.

-------, Jeffrey J. Inman, Murali Mantrala, Eileen Kelley, and Ross Rizley (2011), "Innovations in Shopper Marketing: Current Insights and Future Research Issues," Journal of Retailing, 87S (July), S29-S42.

Sorescu, Alina B. and Jelena Spanjol (2008), “Innovation's Effect on Firm Value and Risk: Insights from Consumer Packaged Goods," Journal of Marketing, 72 (April), 114-132.

Steenkamp, Jan-Benedict E.M. and Inge Geyskens (2014), "Manufacturer and Retailer Strategies to Impact Store Brand Share: Global Integration, Local Adaptation, and Worldwide Learning," Marketing Science 33 (Winter), 6-26.

------ and Katrijn Gielens (2003), "Consumer and Market Drivers of the Trial Probability of New Consumer Packaged Goods,” Journal of Consumer Research, 29 (December), 368-384.

-------, Harald J. van Heerde, and Inge Geyskens (2010), "What Makes Consumers Willing to Pay a Price Premium for National Brands over Private Labels?" Journal of Marketing Research, 47 (December), 1011-1024.

ter Braak, Anne, Marnik G. Dekimpe, and Inge Geyskens (2013a), "Retailer Private-Label Margins: The Role of Supplier and Quality-Tier Differentiation," Journal of Marketing, 77 (July), 86-103.

-------, Barbara Deleersnyder, Inge Geyskens, and Marnik G. Dekimpe (2013b), “Does PrivateLabel Production by National-Brand Manufacturers Create Discounter Goodwill?" International Journal of Research in Marketing, 30 (December), 343-357. 
van Everdingen, Yvonne M., Laurens M. Sloot, Erjen van Nierop, and Peter C. Verhoef (2011), "Towards a Further Understanding of the Antecedents of Retailer New Product Adoption," Journal of Retailing, 87 (December), 579-597.

Zajonc, Robert B. (1984), “On the Primacy of Affect,” American Psychologist, 39 (2), 117-123. 
Table 1: NPs at the Top-13 U.K. Grocery Retail Banners

\begin{tabular}{|c|c|c|c|c|c|c|c|}
\hline Retail banner & $\begin{array}{c}\text { Market share } \\
(\%)\end{array}$ & $\begin{array}{c}\text { Average } \\
\text { penetration within } \\
\text { a category } \\
(\%)\end{array}$ & RBBE & $\begin{array}{c}\text { Average } P L \\
\text { share within } \\
\text { a category } \\
(\%)\end{array}$ & $\begin{array}{c}\text { Number of } \\
\text { adopted } \\
\text { (breakthrough) } \\
\text { NPs }^{\mathbf{b}} \\
\mathbf{n = 1 0 5}(5)\end{array}$ & $\begin{array}{c}\text { Percentage of } \\
\text { NPs adopted } \\
(\%)\end{array}$ & $\begin{array}{l}\text { Average NP } \\
\text { performance }^{c} \\
(\%)\end{array}$ \\
\hline Aldi & 1.47 & 7.06 & 4.23 & 84.18 & $50(3)$ & 47.60 & .17 \\
\hline Asda & 16.14 & 36.55 & 4.83 & 21.24 & $92(5)$ & 87.60 & .88 \\
\hline Iceland & 1.51 & 4.26 & 4.28 & 1.74 & $26(1)$ & 24.80 & 2.94 \\
\hline Lidl & 1.83 & 7.39 & 4.31 & 87.16 & $18(1)$ & 17.10 & .32 \\
\hline Morrisons & 11.00 & 26.96 & 4.50 & 15.34 & $95(5)$ & 90.50 & 1.13 \\
\hline Netto & .82 & 3.53 & 3.82 & 17.62 & $40(2)$ & 38.10 & .61 \\
\hline Sainsbury's & 11.88 & 25.71 & 4.94 & 16.58 & $94(5)$ & 89.50 & 1.09 \\
\hline Somerfield & 2.27 & 7.97 & 3.96 & 10.91 & $80(5)$ & 76.20 & 1.10 \\
\hline Tesco & 17.73 & 41.93 & 5.20 & 19.80 & $94(5)$ & 89.52 & .89 \\
\hline Tesco Express & .50 & 3.18 & 4.40 & 16.70 & $77(5)$ & 73.30 & 1.24 \\
\hline Tesco Extra & 8.12 & 19.08 & 4.59 & 19.05 & $95(5)$ & 90.50 & 1.08 \\
\hline Tesco Metro & .76 & 2.75 & 4.39 & 20.56 & $70(4)$ & 66.70 & .94 \\
\hline Waitrose & 1.53 & 3.73 & 4.31 & 12.46 & $76(5)$ & 72.40 & 1.67 \\
\hline Mean & 5.81 & 14.62 & 4.44 & 21.73 & $70(3.92)$ & 66.50 & 1.07 \\
\hline
\end{tabular}

${ }^{\text {a }}$ Represents the average share of all U.K. panel members that buy in the category at the specific retailer averaged across our 21 categories during our data period.

${ }^{\mathrm{b}}$ An NP is adopted if the retailer adds the product to its assortment within the first year following the NP's market entry. The number of breakthrough NP adoptions is reported between brackets.

${ }^{\mathrm{c}}$ Retailer NP performance is the volume share (\%) of an adopted NP in the category at a given retailer in the first year after its adoption by that retailer. 
Table 2: Measures and Operationalization

\begin{tabular}{|c|c|c|c|}
\hline Variable & Operationalization & Data source & $\begin{array}{l}\text { Supporting } \\
\text { reference }\end{array}$ \\
\hline \multicolumn{4}{|c|}{ Upper-funnel shopper-marketing } \\
\hline Brand equity & $\begin{array}{l}\text { Brand equity was measured by items } 1-16 \text { given under RBBE below. XXX in these items } \\
\text { refers to the brand under which the NP was introduced and "store" is replaced by "product" } \\
\text { in item } 12,14 \& 15 \text {. } \\
\text { Brand equity = [Esteem + Differentiation + Relevance + Energy] / } 4\end{array}$ & $\begin{array}{l}\text { consumer } \\
\text { survey }\end{array}$ & $\begin{array}{l}\text { adapted from } \\
\text { Lehmann et al. } \\
\qquad(2008)\end{array}$ \\
\hline Brand advertising & $\begin{array}{l}\text { National advertising share-of-voice for the mother brand in the category in the year after } \\
\text { retailer adoption. }\end{array}$ & Nielsen Media & $\begin{array}{l}\text { Cleeren et al. } \\
\quad(2013)\end{array}$ \\
\hline NP innovativeness & $\begin{array}{l}=1 \text { if an NP is classified as a breakthrough NP, }-1 \text { otherwise. } \\
\text { A breakthrough NP is an NP that is the first in the industry to offer one or more of the } 6 \\
\text { innovativeness dimensions: (1) positioning the product to new users or usage, (2) providing } \\
\text { a consumer benefit with new packaging, (3) opening up a new market for the product, (4) } \\
\text { merchandising, (5) offering additional value through a new formulation, and (6) introducing } \\
\text { a new technology. }\end{array}$ & $\begin{array}{l}\text { Product Launch } \\
\text { Analytics }\end{array}$ & $\begin{array}{c}\text { Sorescu and } \\
\text { Spanjol (2008) }\end{array}$ \\
\hline \multicolumn{4}{|c|}{ Lower-funnel shopper-marketing } \\
\hline NP price premium & $\begin{array}{l}\text { Price premium of the NP over retailer's category price = ratio of the NP unit price at the } \\
\text { retailer to the weighted category unit price at the retailer (with the respective brands' value } \\
\text { share at the retailer as the weight) in the year after retailer adoption. }\end{array}$ & panel data & $\begin{array}{l}\text { Lamey et al. } \\
\qquad(2012)\end{array}$ \\
\hline NP promotion intensity & $\begin{array}{l}\text { Promotion frequency of the NP at the retailer }=\text { the number of weeks with a negative price } \\
\text { shock of more than } 5 \% \text { of the offering's regular (average) price in the year after retailer } \\
\text { adoption relative to a maximum of } 52 \text { weeks. }\end{array}$ & panel data & $\begin{array}{l}\text { Nijs et al. } \\
(2007)\end{array}$ \\
\hline \multicolumn{4}{|c|}{ C 1} \\
\hline $\begin{array}{l}\text { Retail-banner brand } \\
\text { equity } \\
\text { (RBBE) }\end{array}$ & $\begin{array}{l}\text { 1. I hold XXX in high regard. } \\
\text { 2. XXX is a leader in its field. } \\
\text { 3. XXX has earned a strong reputation. } \\
\text { 4. XXX respects me. } \\
\text { 5. XXX stands out from its competitors. } \\
\text { 6. XXX stands for something unique. } \\
\text { 7. XXX is in a class by itself. } \\
\text { 8. XXX is relevant to me. } \\
\text { 9. XXX is relevant to my family and/or close friends. } \\
\text { 10. XXX is a good one for me. } \\
\text { 11. XXX fits my lifestyle. } \\
\text { 12. I would be tempted to buy in any store of XXX. } \\
\text { 13. XXX is innovative. } \\
\text { 14. I would buy in any type of store concept introduced by XXX. } \\
\text { 15. Based on my experience with XXX, I would strongly consider looking for a XXX store } \\
\text { when I move to a new area. }\end{array}$ & $\begin{array}{l}\text { consumer } \\
\text { survey }\end{array}$ & $\begin{array}{l}\text { adapted from } \\
\text { Lehmann et al. } \\
\qquad(2008)\end{array}$ \\
\hline
\end{tabular}




\begin{tabular}{|c|c|c|c|}
\hline Variable & Operationalization & Data source & $\begin{array}{l}\text { Supporting } \\
\text { reference }\end{array}$ \\
\hline & $\begin{array}{l}\text { 16. XXX constantly introduces NPs. } \\
\text { 17. } \mathrm{XXX} \text { constantly introduces new services. } \\
\text { Esteem }=\Sigma(\text { items } 1-4) / 4 \text {; Differentiation }=\Sigma(\text { items } 5-7) / 3 \text {; Relevance }=\Sigma(\text { items } 8-11) / 4 \text {; } \\
\text { Energy }=\Sigma(\text { items } 12-17) / 6 \text {. Items are scored on } 7 \text {-point Likert scale. } \\
\text { XXX refers to the retail banner in question. } \\
\text { RBBE }=[\text { Esteem }+ \text { Differentiation }+ \text { Relevance }+ \text { Energy }] / 4\end{array}$ & & \\
\hline $\begin{array}{l}\text { Category PL share } \\
\text { (PLS) }\end{array}$ & Value share of the PLs in the category at the retailer in the year prior to retailer adoption. & panel data & $\begin{array}{l}\text { Dhar and Hoch } \\
\text { (1997) }\end{array}$ \\
\hline $\begin{array}{l}\text { Uniqueness in } \\
\text { assortment } \\
\text { (UNIQ) }\end{array}$ & $\begin{array}{l}\left.=1-\left[\sum_{k=1}^{2}\left(\frac{S_{k}}{N}\right)\right] / 2\right) \text { with } S_{\mathrm{k}} \text { the number of sub-brands with a similar value on attribute } k \text { in } \\
\text { the category at the retailer, and } \mathrm{N} \text { the total number of sub-brands in the category at the } \\
\text { retailer in the year after retailer adoption. The two attributes are package size }(\mathrm{k}=1) \text { and } \\
\text { mother brand presence }(\mathrm{k}=2) \text {. If an NP is sold in multiple pack sizes at a retailer, } \mathrm{S}_{1} \text { is } \\
\text { determined as a weighted average across all different NP package sizes offered at the retailer } \\
\text { (with the respective NP package sizes' volume share at the retailer as the weight). }\end{array}$ & panel data & $\begin{array}{l}\text { ter Braak et al. } \\
\quad(2013 a)\end{array}$ \\
\hline \multicolumn{4}{|l|}{ Covariates } \\
\hline Speed of adoption & $\begin{array}{l}=14 \text { - number of retailers (out of the } 13 \text { U.K. retailers in our sample) that already adopted } \\
\text { the NP prior to adoption by the focal retailer. } \\
\text { If the focal retailer did not accept the NP within the } 1^{\text {st }} \text { year after its market launch, it } \\
\text { represents the total number of retailers (out of the } 13 \text { U.K. retailers) that accepted the NP } \\
\text { within the first year after market launch. }\end{array}$ & panel data & $\begin{array}{l}\text { Heeler et al. } \\
\quad(1973)\end{array}$ \\
\hline Hard discounter & $=1$ if the retailer is hard discounter Aldi or Lidl, -1 otherwise. & panel data & \\
\hline State of the economy & $\begin{array}{l}\text { Consumer sentiment index in the U.K. in the year after retailer adoption (measured as an } \\
\text { average over } 12 \text { months). }\end{array}$ & Eurostat & $\begin{array}{l}\text { Lemmens et al. } \\
\text { (2007) }\end{array}$ \\
\hline Category proliferation & $\begin{array}{l}\text { Total number of sub-brands offered in the category at the retailer in the year prior to retailer } \\
\text { adoption. }\end{array}$ & panel data & Gielens (2012) \\
\hline Category concentration & $\begin{array}{l}\text { Sum of the value market shares of the top } 3 \text { brands in the category at the retailer in the year } \\
\text { prior to retailer adoption. }\end{array}$ & panel data & $\begin{array}{l}\text { ter Braak et al. } \\
\text { (2013a) }\end{array}$ \\
\hline Category brand loyalty & $\begin{array}{l}\text { The percentage of respondents that indicated they are brand loyal based on the following } \\
\text { question: "What action would you take when your preferred brand in the category XX is out } \\
\text { of stock?" } \\
1=\text { purchase the desired item at another store } \\
2=\text { buy another type / version / pack size of the same brand at this store } \\
3=\text { buy another brand/shop's own label at the same store } \\
4=\text { return to the store another day to buy the brand I wanted } \\
\text { Respondent is classified as brand loyal if s/he chooses option } 1 \text { or } 2 .\end{array}$ & $\begin{array}{l}\text { consumer } \\
\text { survey }\end{array}$ & $\begin{array}{l}\text { Corstjens and } \\
\text { Corstjens } \\
(1995)\end{array}$ \\
\hline $\begin{array}{l}\text { Difficulty of making the } \\
\text { category }\end{array}$ & $\begin{array}{l}\text { "In the category } X X, \text { making good quality products is difficult" } \\
\text { Item is scored on a 5-point Likert scale. }\end{array}$ & $\begin{array}{l}\text { consumer } \\
\text { survey }\end{array}$ & $\begin{array}{l}\text { Steenkamp et } \\
\text { al. (2010) }\end{array}$ \\
\hline
\end{tabular}




\begin{tabular}{|c|c|c|c|}
\hline Variable & Operationalization & Data source & $\begin{array}{l}\text { Supporting } \\
\text { reference }\end{array}$ \\
\hline $\begin{array}{l}\text { Category purchase } \\
\text { frequency }\end{array}$ & $\begin{array}{l}\text { Total number of purchase records in the panel dataset in the category divided by the number } \\
\text { of unique panel members who buy in the category in the year after retailer adoption. }\end{array}$ & panel data & $\begin{array}{l}\text { Steenkamp and } \\
\text { Geyskens } \\
(2014)\end{array}$ \\
\hline $\begin{array}{l}\text { Manufacturer } \\
\text { innovativeness }^{a}\end{array}$ & $\begin{array}{l}\text { Number of NPs launched by the manufacturer in the category over the last } 5 \text { years prior to } \\
\text { retailer adoption relative to the number of brands offered in the U.K. market by the } \\
\text { manufacturer in the category in the year prior to retailer adoption. }\end{array}$ & $\begin{array}{l}\text { Product Launch } \\
\text { Analytics \& } \\
\text { panel data }\end{array}$ & $\begin{array}{c}\text { Sorescu and } \\
\text { Spanjol (2008) }\end{array}$ \\
\hline $\begin{array}{l}\text { Manufacturer power } \\
\text { across categories }^{a}\end{array}$ & Total assets of the manufacturer relative to total assets of the retailer in year 2007. & Orbis & $\begin{array}{l}\text { Ailawadi et al. } \\
\quad(1995)\end{array}$ \\
\hline $\begin{array}{l}\text { Manufacturer power } \\
\text { within the category }\end{array}$ & $\begin{array}{l}\text { Value share of the manufacturer in the category at the retailer in the year prior to retailer } \\
\text { adoption. }\end{array}$ & panel data & $\begin{array}{l}\text { ter Braak et al. } \\
(2013 b)\end{array}$ \\
\hline $\begin{array}{l}\text { Mother brand price } \\
\text { premium }^{a}\end{array}$ & $\begin{array}{l}\text { Price premium of the NP mother brand at the retailer over retailer's category price }=\text { ratio of } \\
\text { the mother brand unit price at the retailer to the weighted category unit price at the retailer } \\
\text { (with the respective brands' value share at the retailer as the weight) in the year prior to } \\
\text { retailer adoption. }\end{array}$ & panel data & $\begin{array}{l}\text { Lamey et al. } \\
\text { (2012) }\end{array}$ \\
\hline
\end{tabular}

${ }^{\text {a }}$ Variable does not directly explain retailer NP performance, but it is added as an additional control variable to the selection equation to control for potential sample selection bias. 
Table 3: Descriptive Statistics and Correlations of the Drivers of NP Performance at the Retailer ${ }^{\mathrm{a}}$

\begin{tabular}{|c|c|c|c|c|c|c|c|c|c|c|c|c|c|c|c|c|c|c|}
\hline & $\operatorname{Mean}^{b}$ & S.D. & & & & & & & Corr & relation & n matri & & & & & & & \\
\hline & & & 1 & 2 & 3 & 4 & 5 & 6 & 7 & 8 & 9 & 10 & 11 & 12 & 13 & 14 & 15 & 16 \\
\hline 1. Brand equity & 4.77 & 0.34 & 1 & & & & & & & & & & & & & & & \\
\hline 2. Brand advertising & 0.36 & 0.26 & 0.65 & 1 & & & & & & & & & & & & & & \\
\hline 3. NP innovativeness & $5.62 \%$ & - & -0.01 & 0.23 & 1 & & & & & & & & & & & & & \\
\hline 4. NP price premium & 1.5 & 1.17 & 0.15 & 0.22 & 0.16 & 1 & & & & & & & & & & & & \\
\hline 5. NP promotion intensity & 0.16 & 0.16 & 0.03 & 0.03 & 0.10 & -0.08 & 1 & & & & & & & & & & & \\
\hline 6. Retail-banner brand equity & 4.52 & 0.37 & -0.02 & -0.02 & -0.01 & -0.06 & 0.41 & 1 & & & & & & & & & & \\
\hline 7. Category private-label share & 0.22 & 0.21 & 0.03 & 0.03 & -0.07 & 0.19 & -0.19 & -0.08 & 1 & & & & & & & & & \\
\hline 8. Uniqueness in assortment & 0.84 & 0.11 & -0.21 & -0.28 & -0.15 & -0.09 & 0.06 & 0.10 & 0.04 & 1 & & & & & & & & \\
\hline 9. Speed of adoption & 8.61 & 3.08 & -0.08 & -0.06 & -0.04 & -0.06 & 0.35 & 0.56 & -0.20 & 0.06 & 1 & & & & & & & \\
\hline 10. Hard discounter & $11.91 \%$ & - & 0.03 & 0.02 & 0.00 & 0.20 & -0.27 & -0.43 & 0.67 & -0.04 & -0.42 & 1 & & & & & & \\
\hline 11. State of the economy & 104.93 & 7.5 & -0.01 & -0.08 & 0.02 & 0.04 & 0.02 & -0.01 & 0.02 & 0.22 & 0.01 & 0.03 & 1 & & & & & \\
\hline 12. Category proliferation & 112.46 & 72.73 & 0.04 & -0.08 & -0.11 & -0.15 & 0.21 & 0.35 & -0.15 & 0.50 & 0.28 & -0.29 & 0.11 & 1 & & & & \\
\hline 13. Category concentration & 0.57 & 0.15 & 0.39 & 0.25 & 0.17 & 0.28 & -0.02 & -0.02 & -0.02 & -0.41 & 0.00 & 0.01 & -0.05 & -0.40 & 1 & & & \\
\hline 14. Category brand loyalty & 0.52 & 0.1 & 0.30 & 0.07 & 0.04 & -0.06 & 0.01 & -0.05 & 0.00 & 0.32 & -0.07 & 0.04 & 0.09 & 0.26 & 0.29 & 1 & & \\
\hline 15. Difficulty of making the category & 2.64 & 0.14 & -0.05 & 0.02 & 0.16 & 0.20 & -0.02 & -0.01 & -0.13 & -0.29 & -0.05 & 0.02 & -0.10 & -0.40 & 0.32 & -0.29 & 1 & \\
\hline 16. Category purchase frequency & 19.44 & 21.49 & 0.04 & -0.14 & -0.15 & -0.02 & 0.04 & -0.02 & 0.05 & 0.37 & -0.05 & -0.02 & 0.07 & 0.48 & -0.30 & 0.06 & -0.16 & 1 \\
\hline
\end{tabular}

\footnotetext{
a Before ln-transformation and mean-centering.

b For NP innovativeness and Hard discounter, we report the percentage of observations having the value of one.
} 
Table 4: Drivers of NP Adoption by the Retailer

\begin{tabular}{|c|c|c|c|}
\hline \multirow{2}{*}{$\begin{array}{l}\text { Variable } \\
\text { Intercept }\left(\beta_{0}\right)\end{array}$} & \multicolumn{2}{|c|}{ Estimate } & \multirow{2}{*}{$\begin{array}{r}Z \text {-value } \\
1.82\end{array}$} \\
\hline & .688 & $*$ & \\
\hline \multicolumn{4}{|l|}{ Shopper-marketing variables } \\
\hline \multicolumn{4}{|l|}{ Upper-funnel shopper marketing } \\
\hline Brand equity $\left(\beta_{1}\right)$ & -.856 & & -1.19 \\
\hline Brand advertising $\left(\beta_{2}\right)$ & -.014 & & -.61 \\
\hline NP innovativeness $\left(\beta_{3}\right)$ & .195 & $* * *$ & 3.03 \\
\hline \multicolumn{4}{|l|}{ Lower-funnel shopper marketing } \\
\hline Price premium at other retailers $\left(\beta_{4}\right)$ & .060 & & .69 \\
\hline Promotion intensity at focal retailer $\left(\beta_{5}\right)$ & 2.049 & $* * *$ & 5.20 \\
\hline \multicolumn{4}{|l|}{ Store context } \\
\hline \multicolumn{4}{|l|}{ Retailer-wide store context } \\
\hline Retail-banner brand equity $\left(\beta_{6}\right)$ & 3.937 & $* * *$ & 3.40 \\
\hline \multicolumn{4}{|l|}{ Category-specific store context } \\
\hline Category PL share $\left(\beta_{7}\right)$ & .837 & & .93 \\
\hline Uniqueness in assortment $\left(\beta_{8}\right)$ & -3.213 & $* * *$ & -3.23 \\
\hline \multicolumn{4}{|l|}{ Covariates } \\
\hline Speed of adoption $\left(\beta_{9}\right)$ & -.050 & & -.30 \\
\hline Hard discounter $\left(\beta_{10}\right)$ & -.541 & $* *$ & -2.07 \\
\hline State of the economy $\left(\beta_{11}\right)$ & -.747 & & -1.08 \\
\hline Category proliferation $\left(\beta_{12}\right)$ & -.023 & & -.08 \\
\hline Category concentration $\left(\beta_{13}\right)$ & -1.136 & $* * *$ & -3.62 \\
\hline Category brand loyalty $\left(\beta_{14}\right)$ & .216 & & .45 \\
\hline Difficulty of making the category $\left(\beta_{15}\right)$ & 4.901 & $* * *$ & 2.92 \\
\hline Category purchase frequency $\left(\beta_{16}\right)$ & .049 & & .30 \\
\hline Manufacturer innovativeness $\left(\beta_{17}\right)$ & .549 & $* * *$ & 8.90 \\
\hline Manufacturer power across categories $\left(\beta_{18}\right)$ & 1.357 & $* * *$ & 2.82 \\
\hline Manufacturer power within the category $\left(\beta_{19}\right)$ & .059 & $*$ & 1.75 \\
\hline Mother brand price premium $\left(\beta_{20}\right)$ & .271 & $* *$ & 2.03 \\
\hline $\begin{array}{l}\text { Pseudo } \mathrm{R}^{2} \\
\mathrm{~N}\end{array}$ & \multicolumn{3}{|c|}{$\begin{array}{c}34.69 \% \\
1,363\end{array}$} \\
\hline
\end{tabular}

Table 5: Model Fit

\begin{tabular}{|c|c|c|c|c|c|}
\hline Model & $\begin{array}{l}\text { Deviance } \\
(-2 \mathbf{L L})\end{array}$ & $\Delta$ Dev & $\mathbf{d f}^{\mathrm{a}}$ & AIC & $\mathbf{R}^{2}$ \\
\hline Model M1 = intercept only & $4,188.76$ & - & - & $4,236.76$ & - \\
\hline Model M2 = M1 + covariates & $3,962.57$ & $226.19 * * *$ & 8 & $4,039.11$ & $23.28 \%$ \\
\hline Model M3 = M2 + store context & $3,925.01$ & $37.56 * * *$ & 3 & $4,008.01$ & $26.30 \%$ \\
\hline Model M4 = M3 + shopper-marketing variables & $3,516.27$ & $408.74 * * *$ & 7 & $3,612.21$ & $53.08 \%{ }^{\mathrm{b}}$ \\
\hline $\begin{aligned} \text { Model M5 }= & \text { M4 }+ \text { interactions shopper marketing with store } \\
& \text { context }\end{aligned}$ & $3,465.64$ & $50.63 * * *$ & 15 & $3,591.61$ & $55.63 \%$ \\
\hline Model M6 = M5 with only interactions at $p<.20$ retained & $3,467.41$ & -1.77 & 5 & $3,583.48$ & $55.52 \%$ \\
\hline
\end{tabular}


Table 6: Drivers of NP Performance at the Retailer

\begin{tabular}{|c|c|c|c|c|}
\hline \multirow{2}{*}{$\begin{array}{l}\text { Variable } \\
\text { Intercept }\left(\gamma_{0}\right)\end{array}$} & \multirow[t]{2}{*}{$\begin{array}{l}\text { Expected } \\
\text { direction }\end{array}$} & \multicolumn{2}{|c|}{ Estimate } & \multirow{2}{*}{$\frac{Z \text {-value }}{-48.91}$} \\
\hline & & -5.214 & $* * *$ & \\
\hline \multicolumn{5}{|l|}{$\begin{array}{l}\text { Shopper-marketing variables } \\
\text { Upper-funnel shopper marketing }\end{array}$} \\
\hline Brand equity $\left(\gamma_{1}\right)$ & + & .909 & $* *$ & 1.69 \\
\hline Brand advertising $\left(\gamma_{2}\right)$ & + & .054 & $* * *$ & 4.33 \\
\hline NP innovativeness $\left(\gamma_{3}\right)$ & + & .100 & $* *$ & 2.28 \\
\hline \multicolumn{5}{|l|}{ Lower-funnel shopper marketing } \\
\hline NP price premium $\left(\gamma_{4}\right)$ & - & -.835 & $* * *$ & -3.73 \\
\hline NP promotion intensity $\left(\gamma_{5}\right)$ & + & 2.386 & $* * *$ & 3.84 \\
\hline \multicolumn{5}{|l|}{ Store context } \\
\hline \multicolumn{5}{|l|}{ Retailer-wide store context } \\
\hline RBBE: Retail-banner brand equity $\left(\gamma_{6}\right)$ & + & .073 & & .06 \\
\hline \multicolumn{5}{|l|}{ Category-specific store context } \\
\hline PLS: Category PL share $\left(\gamma_{7}\right)$ & - & -.825 & $* * *$ & -2.70 \\
\hline UNIQ: Uniqueness in assortment $\left(\gamma_{8}\right)$ & $+/-$ & -3.138 & $* * *$ & -3.84 \\
\hline \multicolumn{5}{|c|}{ Shopper marketing $*$ Store context interactions } \\
\hline RBBE * Brand equity $\left(\gamma_{9}\right)$ & & 9.493 & $* *$ & 2.48 \\
\hline RBBE * Brand advertising $\left(\gamma_{10}\right)$ & & -.186 & $* *$ & -2.02 \\
\hline RBBE * NP innovativeness $\left(\gamma_{11}\right)$ & & 1.305 & $* * *$ & 2.97 \\
\hline $\mathrm{RBBE} * \mathrm{NP}$ price premium $\left(\gamma_{12}\right)$ & & -1.048 & $* *$ & -2.27 \\
\hline RBBE * NP promotion intensity $\left(\gamma_{13}\right)$ & & -17.276 & $* * *$ & -3.61 \\
\hline PLS * Brand equity $\left(\gamma_{14}\right)$ & & -7.486 & $* * *$ & -2.27 \\
\hline PLS * NP price premium $\left(\gamma_{17}\right)$ & & -.531 & $*$ & -1.78 \\
\hline PLS $*$ NP promotion intensity $\left(\gamma_{18}\right)$ & & 4.590 & $*$ & 1.73 \\
\hline UNIQ * NP innovativeness $\left(\gamma_{21}\right)$ & & -1.356 & $* *$ & -2.00 \\
\hline UNIQ $*$ NP promotion intensity $\left(\gamma_{23}\right)$ & & 6.534 & $* *$ & 2.28 \\
\hline \multicolumn{5}{|l|}{ Covariates } \\
\hline Speed of adoption $\left(\gamma_{24}\right)$ & + & -.002 & & -.01 \\
\hline Hard discounter $\left(\gamma_{25}\right)$ & - & -.174 & $*$ & -1.31 \\
\hline State of the economy $\left(\gamma_{26}\right)$ & + & .623 & $* *$ & 1.61 \\
\hline Category proliferation $\left(\gamma_{27}\right)$ & - & -.606 & $* * *$ & -9.33 \\
\hline Category concentration $\left(\gamma_{28}\right)$ & - & -.639 & $* * *$ & -3.90 \\
\hline Category brand loyalty $\left(\gamma_{29}\right)$ & + & .371 & $* *$ & 1.99 \\
\hline Difficulty of making the category $\left(\gamma_{30}\right)$ & + & 3.673 & $* * *$ & 4.10 \\
\hline Category purchase frequency $\left(\gamma_{31}\right)$ & - & -.018 & & -.42 \\
\hline \multicolumn{5}{|l|}{ Copula-based control variables } \\
\hline C_NP price premium $\left(\gamma_{32}\right)$ & & -.019 & & -.17 \\
\hline C_NP promotion intensity $\left(\gamma_{33}\right)$ & & .329 & $* * *$ & 3.21 \\
\hline $\mathrm{R}^{2}$ & & & $55.52 \%$ & \\
\hline $\mathrm{N}$ & & & 907 & \\
\hline
\end{tabular}


Table 7: Substantive Impact of Drivers of NP Performance at the Retailer

\begin{tabular}{|c|c|c|c|}
\hline Main effects & $\begin{array}{l}\text { Market share effect } \\
1 \mathrm{~S} . D . \text { around mean } \\
\text { in percentage points }\end{array}$ & Shopper marketing * store context interactions ${ }^{b}$ & $\begin{array}{l}\text { Market share effect } \\
\text { 1 S.D. around mean in } \\
\text { percentage points }^{\mathrm{a}}\end{array}$ \\
\hline Shopper-marketing variables & & $\begin{array}{l}\text { Moderating effect store context on upper- } \\
\text { funnel shopper-marketing variables }\end{array}$ & \\
\hline Upper-funnel shopper marketing & & Brand equity for high RBBE & $.13 \%$ \\
\hline Brand equity & $.07 \%$ & Brand equity for low RBBE & $.01 \%$ \\
\hline Brand advertising & $.13 \%$ & Brand equity for high PLS & $.02 \%$ \\
\hline NP innovativeness & $.11 \%$ & Brand equity for low PLS & $.18 \%$ \\
\hline Lower-funnel shopper marketing & & Brand advertising for high $\mathrm{RBBE}$ & $.09 \%$ \\
\hline NP price premium & $-.51 \%$ & Brand advertising for low RBBE & $.17 \%$ \\
\hline NP promotion intensity & $.33 \%$ & NP innovativeness for high RBBE & $.23 \%$ \\
\hline Store context & & NP innovativeness for low RBBE & $.04 \%$ \\
\hline Retailer-wide store context & & NP innovativeness for high UNIQ & $.01 \%$ \\
\hline RBBE: Retail-banner brand equity & $.01 \%$ & NP innovativeness for low UNIQ & $.24 \%$ \\
\hline Category-specific store context & & $\begin{array}{l}\text { Moderating effect store context on lower-funnel } \\
\text { shopper-marketing variables }\end{array}$ & \\
\hline PLS: Category PL share & $-.13 \%$ & NP price premium for high $\mathrm{RBBE}$ & $-.57 \%$ \\
\hline UNIQ: Uniqueness in assortment & $-.21 \%$ & NP price premium for low $\mathrm{RBBE}$ & $-.45 \%$ \\
\hline Covariates & & NP price premium for high PLS & $-.50 \%$ \\
\hline Speed of adoption & $.00 \%$ & NP price premium for low PLS & $-.52 \%$ \\
\hline Hard discounter & $-.19 \%$ & NP promotion intensity for high RBBE & $.13 \%$ \\
\hline State of the economy & $.05 \%$ & NP promotion intensity for low RBBE & $.54 \%$ \\
\hline Category proliferation & $-.57 \%$ & NP promotion intensity for high PLS & $.38 \%$ \\
\hline Category concentration & $-.20 \%$ & NP promotion intensity for low PLS & $.26 \%$ \\
\hline Category brand loyalty & $.08 \%$ & NP promotion intensity for high UNIQ & $.32 \%$ \\
\hline Difficulty of making the category & $.21 \%$ & NP promotion intensity for low UNIQ & $.33 \%$ \\
\hline Category purchase frequency & $-.02 \%$ & & \\
\hline
\end{tabular}

${ }^{a}$ Market share effect for NP innovativeness and hard discounter are based on a dichotomous variable (breakthrough NP/hard discounter vs.

incremental NP/other store format).

${ }^{\mathrm{b}}$ High versus low store context (RBBE, PLS, or UNIQ) is defined as one standard deviation above versus below the mean. 
Table 8: Robustness Checks

\begin{tabular}{|c|c|c|c|c|c|c|c|c|c|}
\hline & \multirow[t]{2}{*}{$\begin{array}{l}\text { Focal } \\
\text { model }\end{array}$} & \multicolumn{2}{|c|}{$\begin{array}{c}\text { Alternative } \\
\text { evaluation } \\
\text { window }\end{array}$} & \multirow[t]{2}{*}{$\begin{array}{l}\text { 2-step } \\
\text { estim. }\end{array}$} & \multirow{2}{*}{$\begin{array}{l}\text { Alter- } \\
\text { native } \\
\text { clustering }\end{array}$} & \multirow[t]{2}{*}{$\begin{array}{c}\text { Ln } \\
\text { transform. } \\
\text { DV }\end{array}$} & \multicolumn{3}{|c|}{$\begin{array}{c}\text { Additional } \\
\text { control } \\
\text { variables } \\
\end{array}$} \\
\hline & & $9 \mathrm{~m}$ & $18 \mathrm{~m}$ & & & & $(1)$ & $(2)$ & (3) \\
\hline \multicolumn{10}{|l|}{ Shopper-marketing variables } \\
\hline Brand equity $\left(\gamma_{1}\right)$ & + & $\checkmark$ & $\checkmark$ & $\checkmark$ & $\checkmark$ & $\checkmark$ & $\checkmark$ & $\checkmark$ & $\checkmark$ \\
\hline Brand advertising $\left(\gamma_{2}\right)$ & + & $\checkmark$ & $\checkmark$ & $\checkmark$ & $\checkmark$ & $\checkmark$ & $\checkmark$ & $\checkmark$ & $\checkmark$ \\
\hline NP innovativeness $\left(\gamma_{3}\right)$ & + & n.s. & n.s. & $\checkmark$ & $\checkmark$ & $\checkmark$ & $\checkmark$ & $\checkmark$ & $\checkmark$ \\
\hline NP price premium $\left(\gamma_{4}\right)$ & - & $\checkmark$ & $\checkmark$ & $\checkmark$ & $\checkmark$ & $\checkmark$ & $\checkmark$ & $\checkmark$ & $\checkmark$ \\
\hline NP promotion intensity $\left(\gamma_{5}\right)$ & + & $\checkmark$ & $\checkmark$ & $\checkmark$ & $\checkmark$ & $\checkmark$ & $\checkmark$ & $\checkmark$ & $\checkmark$ \\
\hline \multicolumn{10}{|l|}{ Store context } \\
\hline Retail-banner brand equity (RBBE) $\left(\gamma_{6}\right)$ & 6) n.s. & n.s. & n.s. & n.s. & n.s. & n.s. & n.s. & n.s. & n.s. \\
\hline Category PL share (PLS) $\left(\gamma_{7}\right)$ & - & $\checkmark$ & $\checkmark$ & $\checkmark$ & $\checkmark$ & $\checkmark$ & $\checkmark$ & $\checkmark$ & $\checkmark$ \\
\hline Uniqueness in assortment $\left(\gamma_{8}\right)$ & - & $\checkmark$ & $\checkmark$ & $\checkmark$ & $\checkmark$ & $\checkmark$ & $\checkmark$ & $\checkmark$ & $\checkmark$ \\
\hline \multicolumn{10}{|c|}{ Shopper marketing * store context interactions } \\
\hline RBBE * Brand equity $\left(\gamma_{9}\right)$ & + & $\checkmark$ & $\checkmark$ & $\checkmark$ & $\checkmark$ & $\checkmark$ & $\checkmark$ & $\checkmark$ & $\checkmark$ \\
\hline RBBE * Brand advertising $\left(\gamma_{10}\right)$ & - & $\checkmark$ & $\checkmark$ & $\checkmark$ & $\checkmark$ & $\checkmark$ & $\checkmark$ & $\checkmark$ & $\checkmark$ \\
\hline RBBE $*$ NP innovativeness $\left(\gamma_{11}\right)$ & + & $\checkmark$ & $\checkmark$ & $\checkmark$ & $\checkmark$ & $\checkmark$ & $\checkmark$ & $\checkmark$ & $\checkmark$ \\
\hline RBBE $*$ NP price premium $\left(\gamma_{12}\right)$ & - & $(\sqrt{ })^{\mathrm{a}}$ & n.s. & $\checkmark$ & $\checkmark$ & $\checkmark$ & $\checkmark$ & $\checkmark$ & $\checkmark$ \\
\hline RBBE $*$ NP promotion intensity $\left(\gamma_{13}\right)$ & - & $\checkmark$ & $\checkmark$ & $\checkmark$ & $\checkmark$ & $\checkmark$ & $\checkmark$ & $\checkmark$ & $\checkmark$ \\
\hline PLS $*$ Brand equity $\left(\gamma_{14}\right)$ & - & $\checkmark$ & $\checkmark$ & $\checkmark$ & $\checkmark$ & $\checkmark$ & $\checkmark$ & $\checkmark$ & $\checkmark$ \\
\hline PLS $*$ NP price premium $\left(\gamma_{17}\right)$ & - & $\checkmark$ & $\checkmark$ & $\checkmark$ & $\checkmark$ & $\checkmark$ & $\checkmark$ & $\checkmark$ & $\checkmark$ \\
\hline PLS * NP promotion intensity $\left(\gamma_{18}\right)$ & + & n.s. & $\checkmark$ & $(\sqrt{ })^{\mathrm{a}}$ & $\checkmark$ & $\checkmark$ & $\checkmark$ & $\checkmark$ & $\checkmark$ \\
\hline UNIQ * NP innovativeness $\left(\gamma_{21}\right)$ & - & $\checkmark$ & $\checkmark$ & $\checkmark$ & $\checkmark$ & $\checkmark$ & $\checkmark$ & $\checkmark$ & $\checkmark$ \\
\hline UNIQ * NP Promotion intensity $\left(\gamma_{23}\right)$ & + & $(\sqrt{ })^{\mathrm{a}}$ & $\checkmark$ & $\checkmark$ & $\checkmark$ & $\checkmark$ & $\checkmark$ & $\checkmark$ & $\checkmark$ \\
\hline \multicolumn{10}{|l|}{ Covariates } \\
\hline Speed of adoption $\left(\gamma_{24}\right)$ & + & $\checkmark$ & $\checkmark$ & $\checkmark$ & $\checkmark$ & $\checkmark$ & $\checkmark$ & $\checkmark$ & $\checkmark$ \\
\hline Hard discounter $\left(\gamma_{25}\right)$ & - & $\checkmark$ & $(\sqrt{ })^{\mathrm{a}}$ & $(\sqrt{ })^{\mathrm{a}}$ & $\checkmark$ & $\checkmark$ & $\checkmark$ & $(\sqrt{ })^{\mathrm{a}}$ & n.s. \\
\hline State of the economy $\left(\gamma_{26}\right)$ & + & $\checkmark$ & $\checkmark$ & $\checkmark$ & $\checkmark$ & $\checkmark$ & $\checkmark$ & $\checkmark$ & $\checkmark$ \\
\hline Category proliferation $\left(\gamma_{27}\right)$ & - & $\checkmark$ & $\checkmark$ & $\checkmark$ & $\checkmark$ & $\checkmark$ & $\checkmark$ & $\checkmark$ & $\checkmark$ \\
\hline Category concentration $\left(\gamma_{28}\right)$ & - & $\checkmark$ & $\checkmark$ & $\checkmark$ & $\checkmark$ & $\checkmark$ & $\checkmark$ & $\checkmark$ & $\checkmark$ \\
\hline Category brand loyalty $\left(\gamma_{29}\right)$ & + & $\checkmark$ & $\checkmark$ & $(\sqrt{ })^{\mathrm{a}}$ & $\checkmark$ & $\checkmark$ & $\checkmark$ & $\checkmark$ & $\checkmark$ \\
\hline Difficulty of making the category $\left(\gamma_{30}\right)$ & + & $\checkmark$ & $\checkmark$ & $\checkmark$ & $\checkmark$ & $\checkmark$ & $\checkmark$ & $\checkmark$ & $\checkmark$ \\
\hline Category purchase frequency $\left(\gamma_{31}\right)$ & n.s. & n.s. & n.s. & n.s. & n.s. & n.s. & n.s. & n.s. & n.s. \\
\hline \multicolumn{10}{|l|}{ Additional control variables } \\
\hline Retailer NP activity (1) & & & & & & & + & & \\
\hline Seasonal dummies (2) & & & & & & & & $(+)^{\mathrm{b}}$ & \\
\hline Convenience store format (3) & & & & & & & & & + \\
\hline
\end{tabular}

$\checkmark$ indicates that the parameter is similar in both sign and significance $(p<.10)$ to the focal model results.

${ }^{a}$ Even though the parameter is robust in sign and magnitude, it has a $p$-value between .10 and .15, just outside the $10 \%$ significance level.

${ }^{\mathrm{b}} \mathrm{NPs}$ introduced in quarter 3 perform better relative to the other quarters $(1,2$, and 4$)$. 
Table 9: Summary of Findings

\begin{tabular}{|c|c|c|c|}
\hline Driver of NP performance & $\begin{array}{c}\text { Direction } \\
\text { of the } \\
\text { overall } \\
\text { effect }\end{array}$ & $\begin{array}{l}\text { Magnitude of } \\
\text { effect on NP } \\
\text { performance }\end{array}$ & Implications \\
\hline
\end{tabular}

\section{Shopper-marketing variables}

Upper-funnel shopper marketing

Brand equity for low PLS

categories and high RBBE

retailers

Brand advertising for low

RBBE retailers

NP innovativeness for high

RBBE retailers and for NP

with low uniqueness in the

assortment

Lower-funnel shopper marketing

$\mathrm{NP}$ price premium

Negative

Large

NP promotion intensity

Positive

Large

\section{Store context}

Retailer-wide store context

Retail-banner brand equity

(RBBE)

Category-specific store context

Category PL share (PLS)

Negative

Medium

Uniqueness in assortment

(UNIQ)

Medium

Negative Medium
Brand equity is of medium importance in categories where the retailer's PL is weak and for high RBBE retailers. In other situations, brand equity has a negligible effect on NP performance.

Brand advertising does contribute to NP performance although the effect is only of medium importance and has only a small effect for high RBBE retailers.

The effect of NP innovativeness differs strongly across retailers in function of their RBBE and the uniqueness of the innovation in the retailer's category assortment. Breakthrough NPs do especially well at high RBBE retailers and in assortments where they are less unique. The effect of NP innovativeness is small at a low RBBE retailer and in assortments where the NP is more unique.

Although the effect of NP price premium is moderated by RBBE and PLS, it is always large. A large price premium versus the category price level at that retailer reduces NP performance at any retailer. Apart from category proliferation, price premium has the largest generalized effect on retailer NP performance.

The effect of NP promotion intensity is large across different levels of PLS and UNIQ in the category and for all retailers but high RBBE retailers, where the effect of promotion intensity is only medium. At low RBBE retailers, heavy promotions is absolutely crucial for NP performance.

The main effect of RBBE per se is negligible. That means that an NP can succeed in highly regarded and less-highly regarded retailers. However, RBBE does moderate the effects of all five shoppermarketing variables. This underlines the importance of tailoring NP introduction strategies to individual retailers - a core tenet of shopper marketing.

The overall effect of category PLS is medium. However, PLS also systematically affects the effects of NP price premium, NP promotion intensity and especially brand equity (see above) performance. The effect size is medium. However, UNIQ also systematically affects the impact of NP promotion intensity and especially NP innovativeness. 


\begin{tabular}{|c|c|c|c|}
\hline Driver of NP performance & $\begin{array}{l}\text { Direction } \\
\text { of the } \\
\text { overall } \\
\text { effect }\end{array}$ & $\begin{array}{l}\text { Magnitude of } \\
\text { effect on NP } \\
\text { performance }\end{array}$ & Implications \\
\hline \multicolumn{4}{|l|}{ Covariates } \\
\hline Speed of adoption & Null & - & NP performance at the retailer does not depend on the retailer's speed of adoption. \\
\hline Hard discounter & Negative & Medium & $\begin{array}{l}\text { NP performance is lower at hard discounters. This suggests that manufacturers' growing interest to } \\
\text { introduce their brands at hard discounters (Deleersnyder and Koll 2012) should push their mature } \\
\text { products rather than NP offerings in such outlets. }\end{array}$ \\
\hline State of the economy & Positive & Small & $\begin{array}{l}\text { NP performance is higher when they are introduced by the retailer under favorable economic } \\
\text { conditions. However, the effect is small. This supports recommendations to ramp up NP activity in } \\
\text { economically tough times to fight the growth of PLs (Lamey et al. 2012) as one can expect only a } \\
\text { minor downward effect on NP performance. }\end{array}$ \\
\hline Category proliferation & Negative & Large & $\begin{array}{l}\text { NPs have greater difficulty in capturing market share in categories with many product types and sub- } \\
\text { brands. This is the single most important generalized driver of NP performance. }\end{array}$ \\
\hline Category concentration & Negative & Medium & NPs are less successful in highly concentrated categories. \\
\hline Category brand loyalty & Positive & Small & $\begin{array}{l}\text { The small effect size suggests that NPs can be successful in both categories characterized by high brand } \\
\text { loyalty and categories where shoppers are primarily loyal to their store rather than to any particular } \\
\text { brand. }\end{array}$ \\
\hline $\begin{array}{l}\text { Difficulty of making the } \\
\text { category }\end{array}$ & Positive & Medium & $\begin{array}{l}\text { NPs are more successful in categories where consumers think it is difficult to make a good quality } \\
\text { product. }\end{array}$ \\
\hline Category purchase frequency & Null & - & NP performance does not depend on how often consumers buy the category. \\
\hline
\end{tabular}




\section{Figure 1: Research Framework}
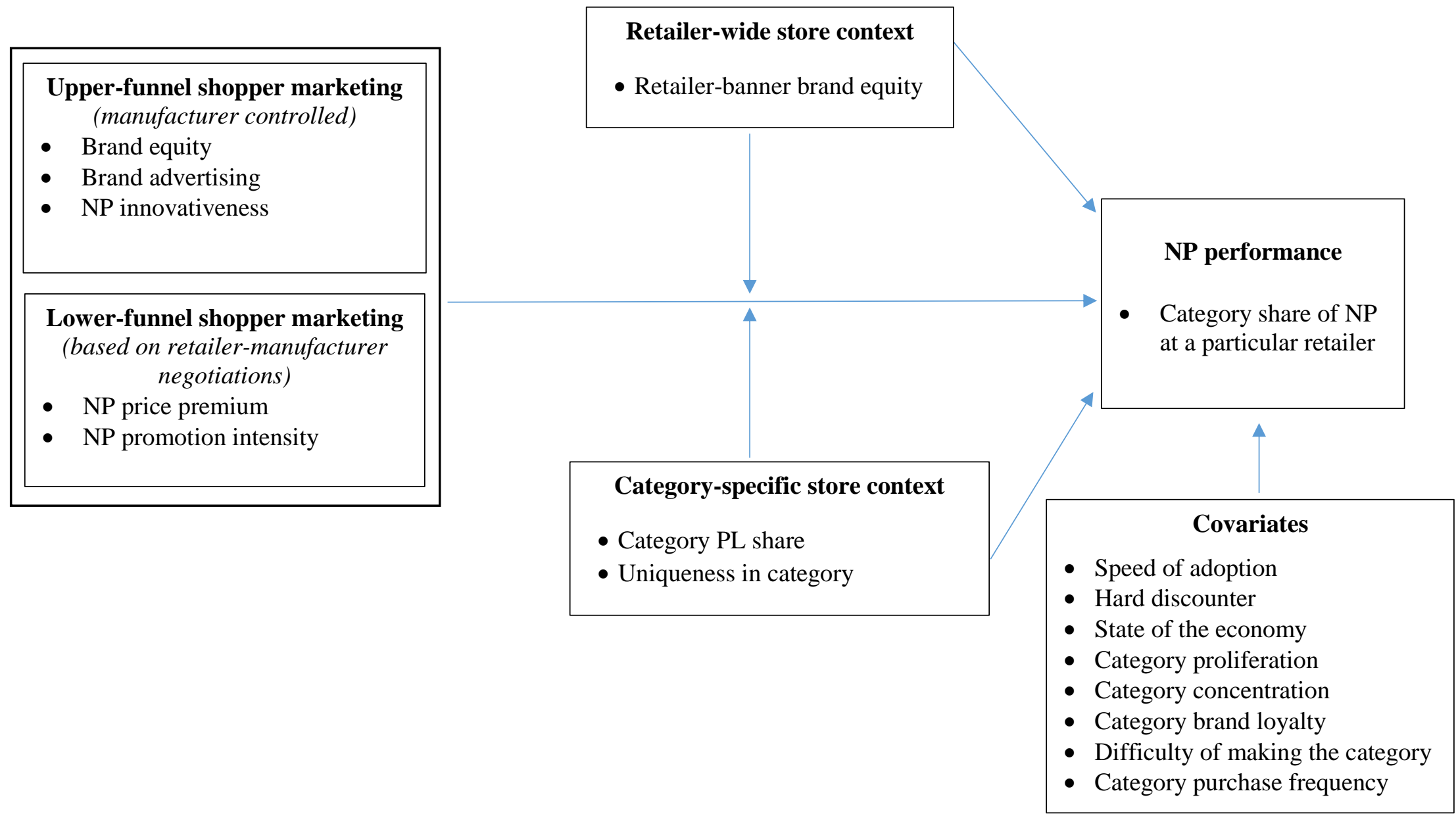
Figure 2: Moderating Effect of Store Context on the Impact of Upper-Funnel Shopper-Marketing Variables on NP Performance $^{\mathrm{a}}$

PANEL A: Retail-banner brand equity (RBBE)
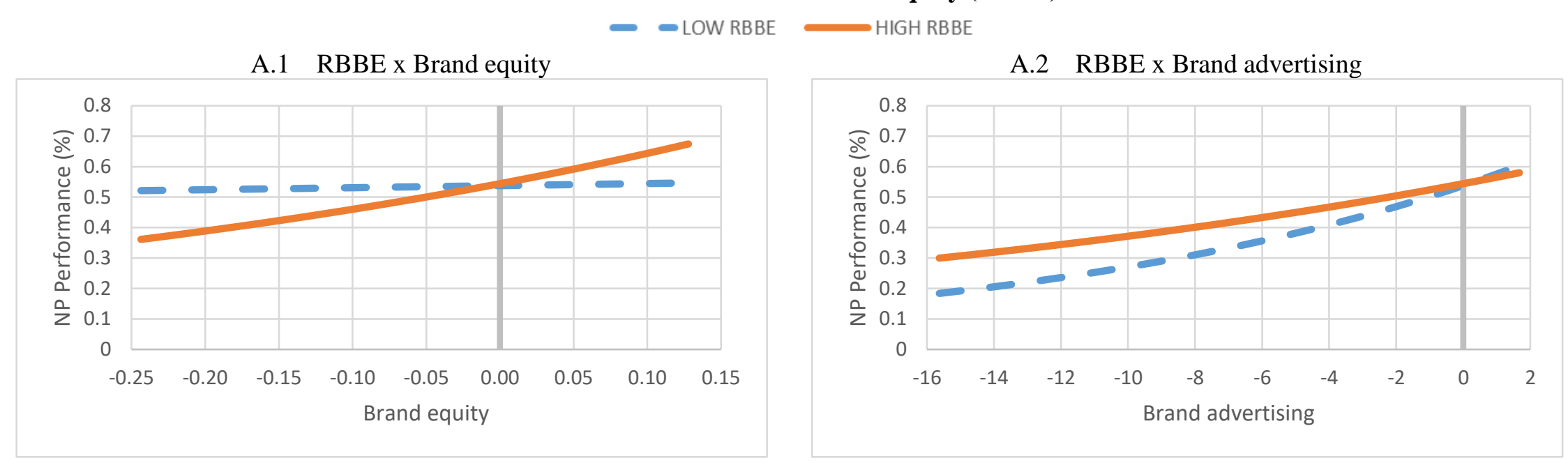

A.3 RBBE x NP innovativeness

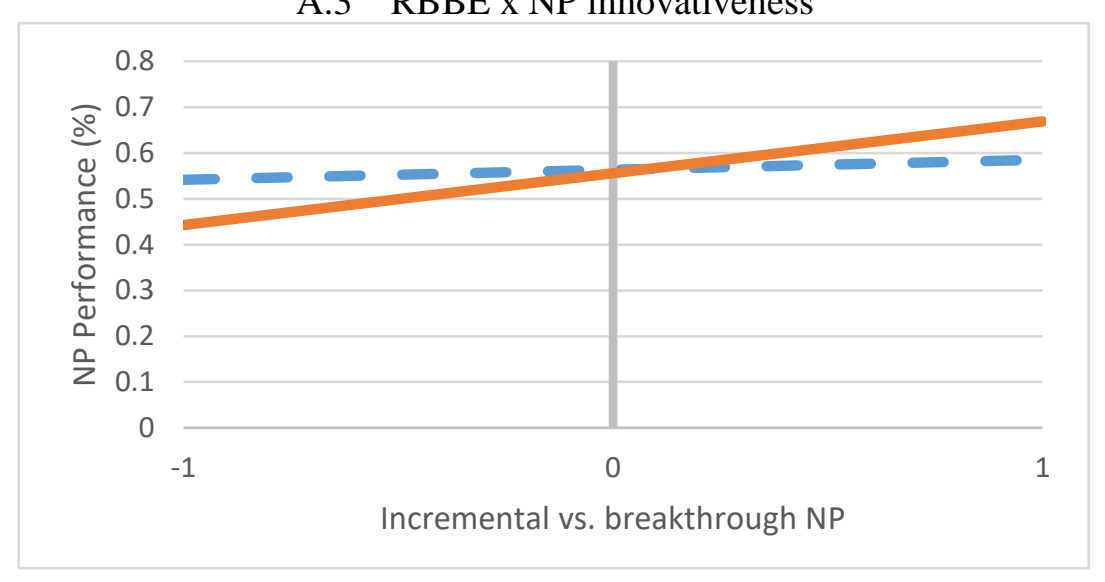


PANEL B: Category PL share (PLS)

- LOW PLS HIGH PLS

B.1 PLS x Brand equity

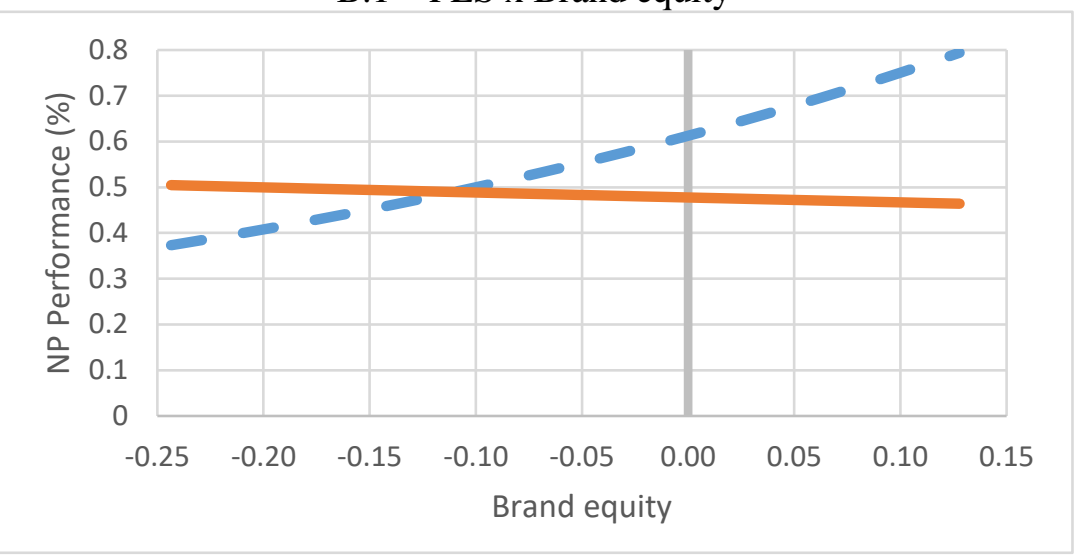

PANEL C: Uniqueness in assortment (UNIQ)

- low UNIQ

high UNIQ

C.1 UNIQ x NP innovativeness

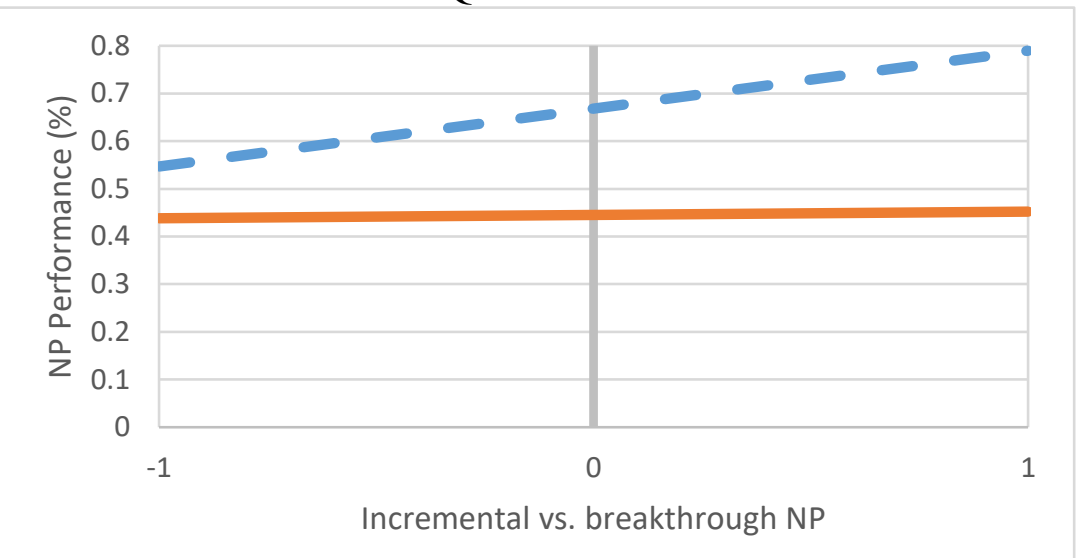

${ }^{a}$ The X-axis covers for the respective upper-funnel shopper-marketing variable the full range of the mean-centered ln-transformed variable as used in Equation 1 (going from the minimum value to the maximum value observed in our data). The Y-axis quantifies the NP share at the retailer holding all other continuous variables at their mean level (or zero for the effect-coded dummy variables). Low (high) values for store context (RBBE, PLS, and UNIQ) are defined as one standard deviation below (above) the variable's mean. 
Figure 3: Moderating Effect of Store Context on the Impact of Lower-Funnel Shopper-Marketing Variables on NP Performance $^{\text {a }}$

PANEL A: Retail-banner brand equity (RBBE)

- LOW RBBE HIGHRBBE

A.1 RBBE x Price premium

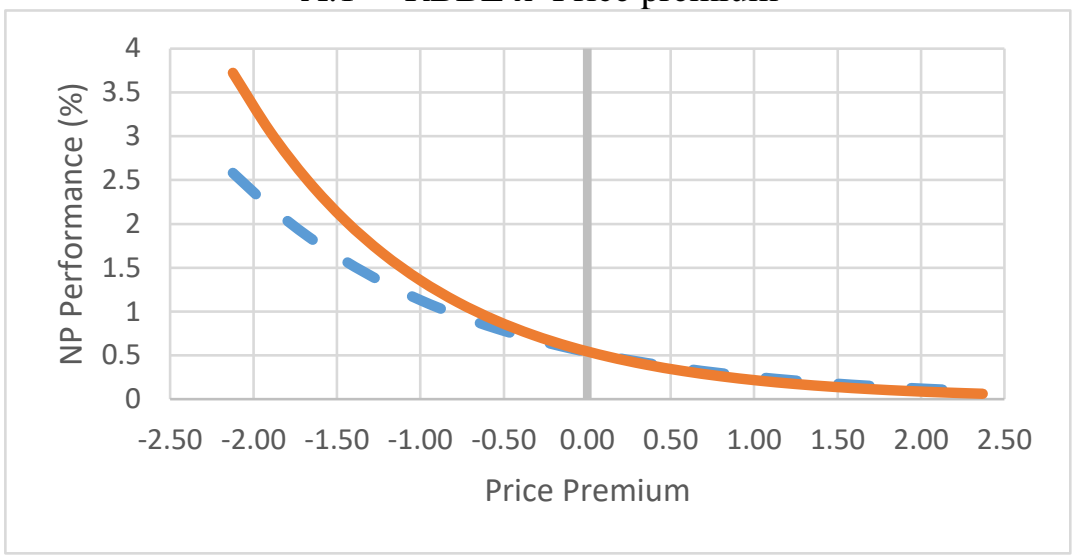

A.2 RBBE $x$ Promotion intensity

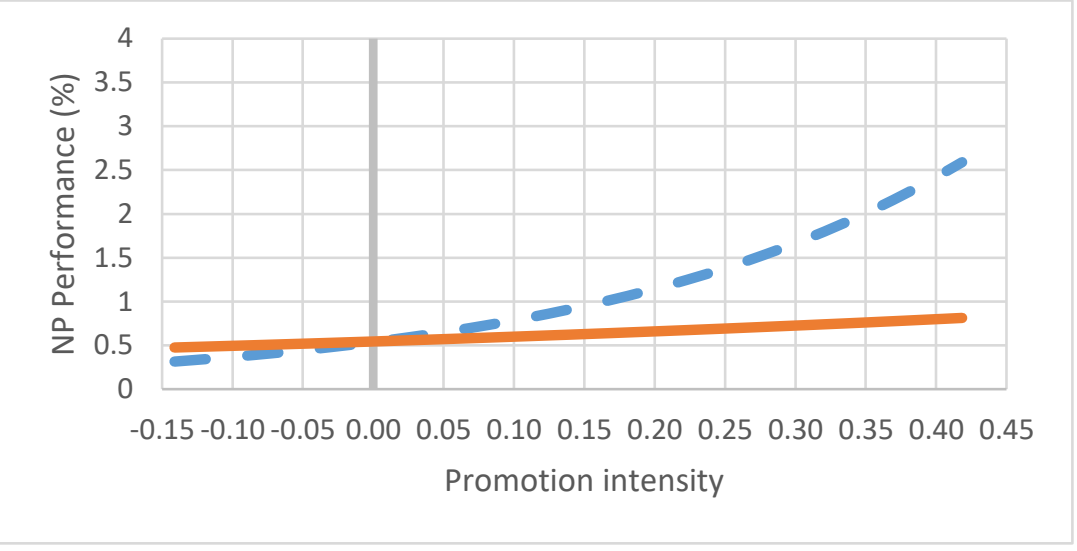

\section{PANEL B: Category PL share (PLS)}

- - LOW PLS

B.1 PLS x Price premium

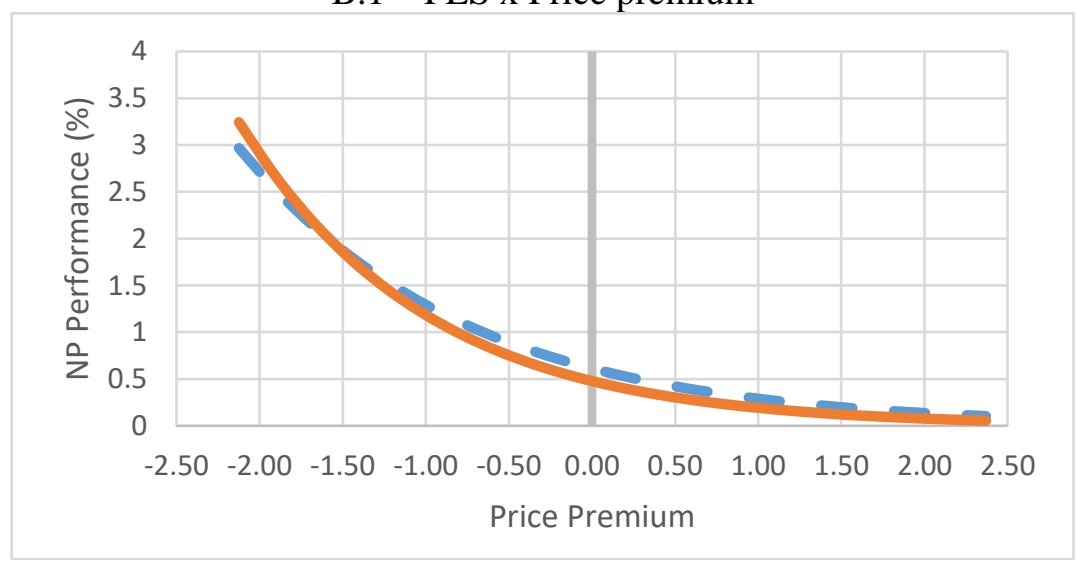

B.2 PLS x Promotion intensity

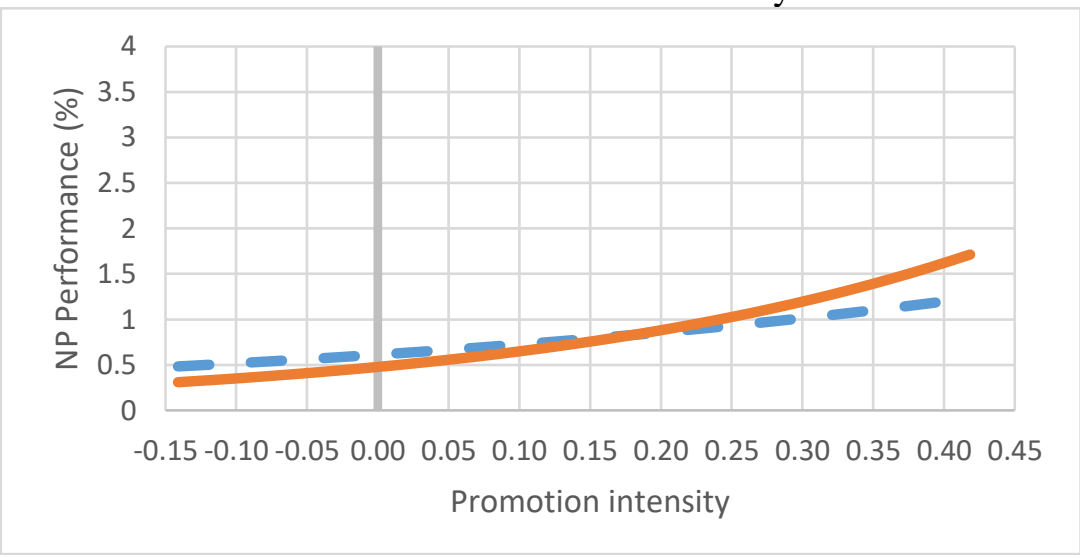


PANEL C: Uniqueness in assortment (UNIQ)

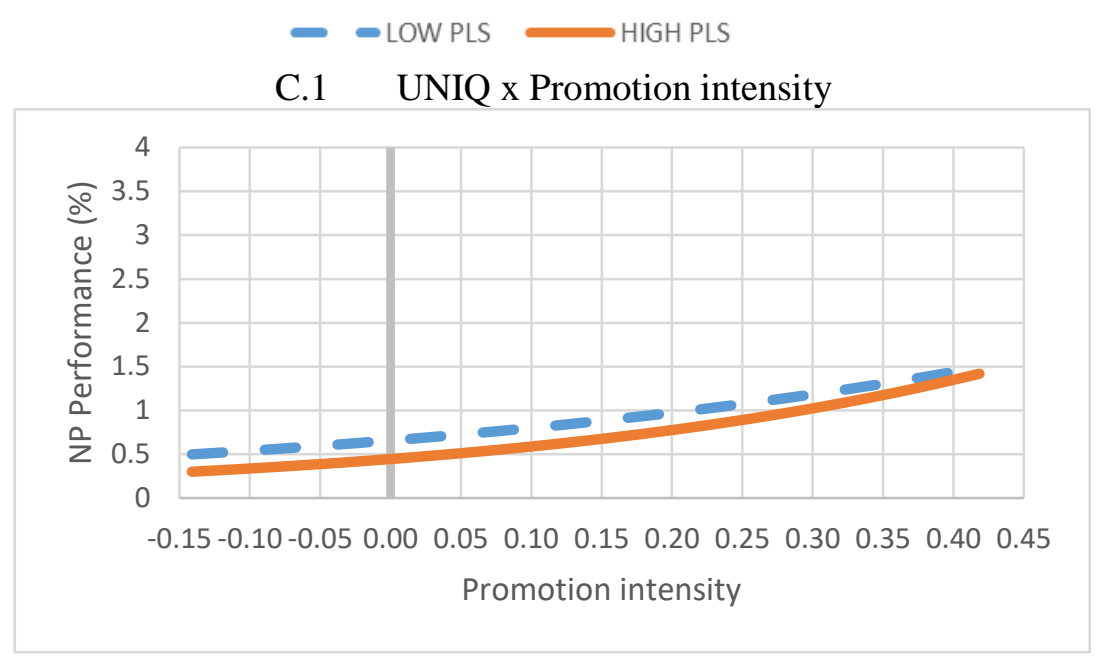

${ }^{a}$ The $\mathrm{X}$-axis covers for the respective lower-funnel shopper-marketing variable the full range of the mean-centered ln-transformed variable as used in Equation 1 (going from the minimum value to the maximum value observed in our data). The Y-axis quantifies the NP share at the retailer holding all other continuous variables at their mean level (or zero for the effect-coded dummy variables). Low (high) values for store context (RBBE, PLS, and UNIQ) are defined as one standard deviation below (above) the variable's mean. 